\title{
Revisiting the dynamics of catastrophic late Pleistocene glacial-lake drainage, Altai Mountains, central Asia
}

\author{
P. Bohorquez ${ }^{\mathrm{a}, *}$, P.J. Jimenez-Ruiz ${ }^{\mathrm{b}}$, P.A. Carling ${ }^{\mathrm{c}}$ \\ ${ }^{a}$ Centro de Estudios Avanzados en Ciencias de la Tierra (CEACTierra), Universidad de Jaén. Campus de \\ las Lagunillas, 23071 Jaén, Spain \\ ${ }^{b}$ Área de Mecánica de Fluidos, Departamento de Ingeniería Mecánica y Minera, Universidad de Jaén. \\ Campus de las Lagunillas, 23071 Jaén, Spain \\ ${ }^{c}$ Geography and Environment, University of Southampton, Southampton, UK
}

\begin{abstract}
In this work, we present a whole system model of megafloods from catastrophic ice-dam failure in the late Pleistocene that comprises the study of the dynamics of the glacial lake, the propagation of the flood wave downstream of the dam, and an approximation to the ice breach process. The ice-dam incision rate was simply considered an unknown constant, which was varied systematically to best fit the maximum altitude of the simulated water surface and the paleostage indicators in the downstream valley during the transient megaflood. Hence, the hydrograph resulting from the breach of the ice dam was not prescribed but was an output of the paleohydraulic reconstruction.

By considering two possible configurations of the breach in the ice dam, i.e. full or partial removal of the ice, we constrained the incision rate in the narrow range of $28-42 \mathrm{~m} \cdot \mathrm{h}^{-1}$. Two connected glacial lakes, Kuray and Chuja, released $95 \%$ of the stored water volume (i.e., $564 \mathrm{~km}^{3}$ ) in 33.8 hours. A peak discharge of $10.5 \mathrm{M} \mathrm{m}^{3} \cdot \mathrm{s}^{-1}$ was required to form numerous giant bars and run-up deposits in the Chuja and Katun valleys. The peak streamflow occurred after 11 hours when $45 \%$ of the available lake volume had been evacuated from the Kuray and Chuja basins. Further verification of the reconstructed megaflood was achieved by studying the computed hydraulic conditions during the lake draining that justify the existence and orientation of several fields of subaqueous gravel-dunes in the glacial lake. Complex spatiotemporal patterns during the recession stage of the flood built most of the fields of bedforms. In terms of nondimensional parameters, the Froude and Shields numbers that formed the dune fields were similar to those observed in large sandy rivers, but the flow was undoubtedly unsteady and two-dimensional.

We conclude by noting that the extensions of the simulated area cannot be cropped or analysed by independent parts in order to predict the formation of the most relevant geological records due to the unsteady, two-dimensional nature of the flow motion and the development of backwater effects in the drainage network. Lastly, the paleohydrological reconstruction of a megaflood has helped not only to infer the dynamics of the event but also to retrodict the mean parameters of the ice-dam failure mechanism.
\end{abstract}

Keywords: lake drainage, megaflood, giant gravel dunes, Altai Mountains, paleohydrology

\section{Introduction}

The Altai megaflood case study has attracted and motivated a number of studies for more than two decades. The exceptional geological records of this case study include un-

\footnotetext{
${ }^{*}$ Corresponding author.

Email address: patricio.bohorquez@ujaen.es (P. Bohorquez)
} 
ambiguous details on the paleoshorelines of glacial Lake Kuray-Chuja (Carling et al., 2002, 2011). The large field of bedforms sculpted in the basins during the lake drainage (Fig. 1a) include the most notable example of giant gravel dunes on Earth (Carling, 1996a, 1999), the paleohydraulic significance of which has been recently revisited (Carling et al., 2016). Intricate two-dimensional currents in the Kuray Basin provoked the formation of the dunefields (Rudoy, 2002; Inishev et al., 2015; Bohorquez et al., 2016). A set of numerous giant bars and run-up sediments filled the Chuja Valley after the breach of the ice-dam, see Fig. 1b, and delimit the maximum flood levels (Baker et al., 1993; Rudoy and Baker, 1993; Herget, 2005; Carling et al., 2009b; Carling, 2013) necessary to reconstruct the magnitude of the event (see also Carling et al., 2010).

The paleohydrological reconstruction of the Altai megaflood has progressively evolved in time regarding the complexity of the methods and the physical processes that can be modelled. The basis of the earliest reconstructions by Baker et al. (1993) and Herget (2005) was a simplified version of the one-dimensional shallow water equations for steady flow, referred to as the step-backwater equation. This technique is a standard for paleohydraulic reconstruction in confined valleys (Feldman, 1981; Lumbroso and Gaume, 2012; Herget et al., 2014; Bohorquez, 2016), where an increase in flood discharge results in a large increase in the stage (Baker, 1987). The application of step-backwater analysis in the glacier-filled area and the downstream Chuja Valley yielded peak discharges of 18.5 (Baker et al., 1993) and 8-10 $\mathrm{M} \mathrm{m}^{3} \cdot \mathrm{s}^{-1}$ (Herget, 2005). Refined estimates of the peak streamflow could be obtained from unsteady, two-dimensional shallow water modelling of flow routing downstream of the dam, which yields 9-11 $\mathrm{M} \mathrm{m}^{3} \cdot \mathrm{s}^{-1}$ (Carling et al., 2010). Furthermore, the two-dimensional Saint-Venant equations allow the computation of the water level and velocity vector at spatial scales as high as the best resolution of available digital elevation models for Earth (presently, about $30 \mathrm{~m}$ ). In all these studies morphological changes were neglected by assuming a fixed bed where the approach is consistent with the lack of significant changes in basin capacity in the late Pleistocene. The assumption was proved correct in later dynamical simulations of the Altai megaflood over a moveable bed (Huang et al., 2014, 2015).

The paleohydraulic reconstruction methods enumerated above converged at predicting the magnitude of the unknown peak discharge. However, there are additional details of 
interest on the timing of the megaflood. For instance, the specific shape of the hydrograph and the peak time continue to be unknown and still require a physical model. Herget (2005) estimated a flood that did not last for more than 2-3 days based on a $10 \mathrm{M} \mathrm{m}^{3} \cdot \mathrm{s}^{-1}$ peak discharge. His theoretical hydrograph of the ice-dammed lake outburst flood yields a peak time of 16.8 hours. Also, the time and the hydraulic conditions required to form the bedforms in the lake basin remain an open question. The novel paleohydraulic reconstruction method proposed in this work is based on the coupled model of the ice-dam breach failure, the dynamical simulation of the glacial-lake drainage and the flood routing along the drainage network downstream the ice dam. The unknown parameter to be determined is the mean value of the melt rate of ice, and among the more relevant output parameters are the water depth, velocity magnitude, hydrograph, shear stress and flow direction as a function of time. Nondimensional groups such as the Froude number and Shields parameter can then be evaluated at locations of interest (e.g. Bohorquez et al., 2016).

The methodology employed here is not limited to the Altai megaflood study case as it could be applied in the future to other events worldwide. For instance, one could reconstruct from high-magnitude (Carrivick, 2006) to small-magnitude outburst floods (Bohorquez and Darby, 2008), the catastrophic late Pleistocene glacial-lake drainage such as the largest Missoula draining (Alho et al., 2010; Denlinger and O'Connell, 2010), the flood at the margin of the Middle Pleistocene Scandinavian Ice Sheet (Winsemann et al., 2016) and the lake Bonneville flood (Abril-Hernández et al., 2018). All these studies have used unsteady twodimensional shallow-water modelling and may take advantage of a whole-system model.

The paper is organised as follows: the paleohydraulic reconstruction method (i.e., an overview of the hydraulic modelling technique, the initial conditions of the lake, possible ice-dam failures and the procedure followed to infer the ice incision rate) is presented in Section 2. Numerical results are described in Section 3. We focus on the description of the dynamics of the flood wave (Section 3.1), the Kuray-Chuja lake (Section 3.2) and the hydraulic conditions that allowed the developments of megaflood scale bedforms (Section 3.3). The similarities and differences between the modelled scenarios are also discussed (Section 3.4). Subsequently, discussions and comparisons with previous paleoreconstructions are given in Section 4. Conclusions are finally drawn in Section 5. 


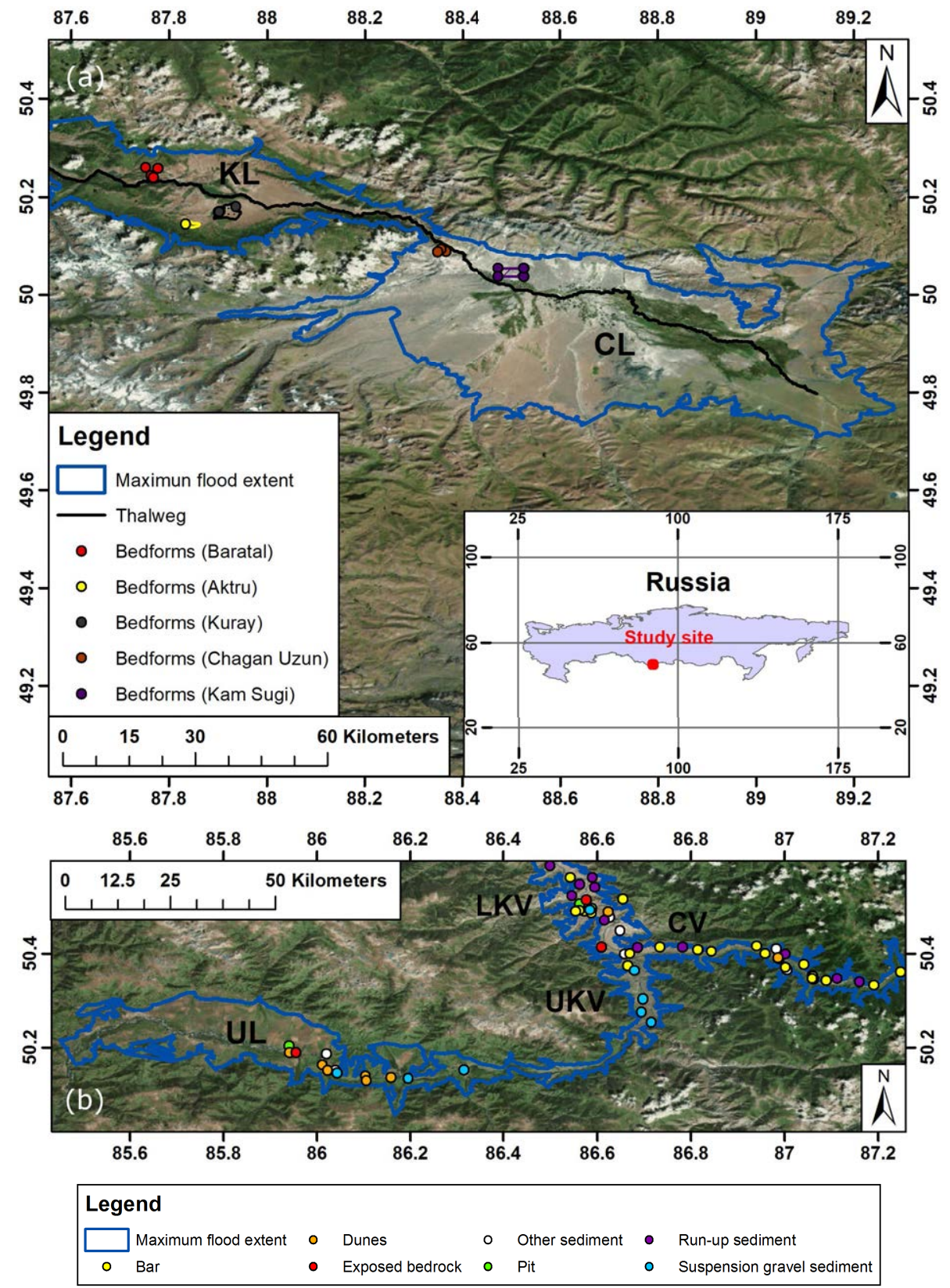

Fig. 1: Location map of Kuray and Chuja lakes (panel a) showing the areas covered by gravel-dunes fields (e.g. Carling, 1996a; Rudoy, 2002), giant bars and run-up sediments (e.g. Baker et al., 1993; Carling et al., 2009b), paleoshorelines of glacial Lake Kuray-Chuja (Carling et al., 2011), among other geological evidence of the Late Pleistocene Altai Megaflood (Siberia) downstream of the ice dam (panel b). Details for local settings of such features can be found in Rudoy and Baker (1993), Carling et al. (2002) and Herget (2005). KL: Kuray Lake; CL: Chuja Lake; UL: Uimon Lake; CV: Chuja Valley; UKV: Upper Katun Valley; LKV: Lower Katun Valley. Northings and eastings in degrees. 


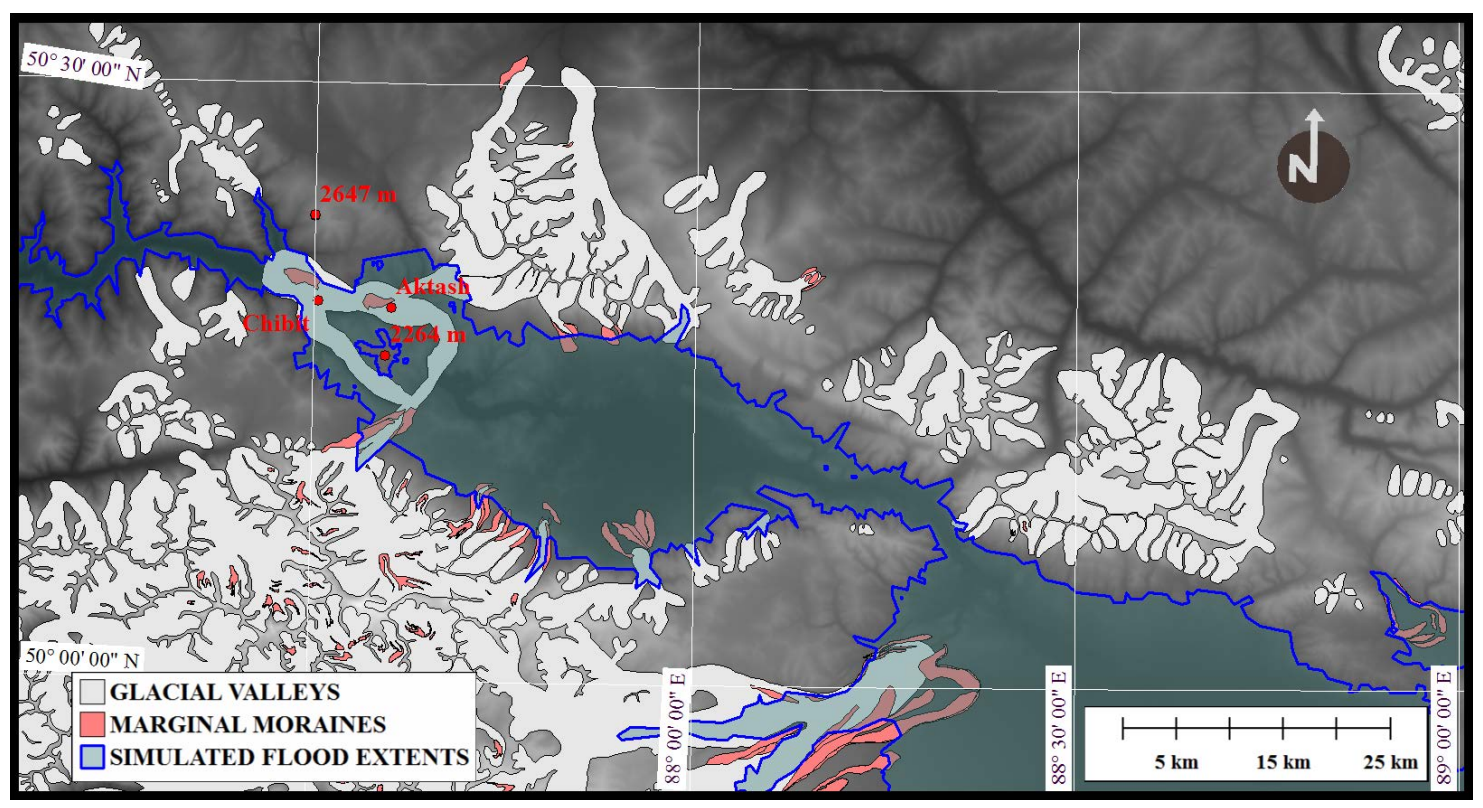

Fig. 2: Aerial extent of the glacier dimensions around the Kuray lake in the Altai Mountains (white area), forming the ice dam in the glacial valley near the towns of Chibit and Aktash (Blomdin et al., 2016). Marginal moraines are shown in pink (Rudoy, 2002; Herget, 2005; Reuther et al., 2006). The blue area represents the simulated flood extent for the full breach of the ice dam.

\section{Paleohydraulic reconstruction method}

\subsection{Computational domain, model equations and initial conditions}

Following Bohorquez et al. (2016), we adopt an unsteady hydraulic modelling approach to retrodict the dynamics of the catastrophic late Pleistocene glacial-lake drainage in the Altai Mountains. The main difference concerning our previous work is that the study domain was not limited to the Kuray and Chuja lakes (Fig. 1a); rather we have included all of the relevant drainage network downstream of the ice dam (Fig. 1b). Both regions were connected through a glacier-filled area, see Fig. 2, that progressively breached and released masses of water stored in the conjoined Kuray and Chuja lakes. As an initial condition, we set the glacial lake at an elevation of $2100 \mathrm{~m}$ (Carling et al., 2011), which is equivalent to the volume $564 \mathrm{~km}^{3}$.

The computational domain includes all those locations where geological paleostage indicators (PSIs) exist (Herget, 2005). It accounts for the Kuray-Chuja lakes (Fig. 1a) upstream of the glaciated area covered by the ice dam near Aktash (Fig. 2), the Chuja valley that 
initially routed the megaflood downstream of the dam, and the Katun valley that bifurcated the flow at the end of the Chuja valley (see Fig. 1b). The outflow boundary condition was the north of Katun river (at the top of Fig. 1b). The total area of the computational domain amounts to $5885 \mathrm{~km}^{2}$. Therein, the most frequent PSIs include subaqueous gravel-dune fields in the lakes, as well as giant bars and run-up sediments in the downstream valleys. Our paleohydraulic study accounts for all of this evidence.

The two-dimensional shallow-water equations, better known as the Saint-Venant equations, were adopted to describe the motion of the water phase. We solved numerically the depth-averaged inviscid conservation laws of mass and momentum for clear water in a twodimensional, Cartesian system of coordinates, which are written in compact form as

$$
\begin{gathered}
\frac{\partial h}{\partial t}+\nabla \cdot(h \boldsymbol{u})=0, \\
\frac{\partial h \boldsymbol{u}}{\partial t}+\nabla \cdot(h \boldsymbol{u} \boldsymbol{u})+\nabla\left(\frac{g h^{2}}{2}\right)=-g h \nabla z-\frac{\boldsymbol{\tau}_{b}}{\rho},
\end{gathered}
$$

where $t$ is the time, $h$ is the depth of the water measured along the vertical coordinate, $\boldsymbol{u}$ is the depth-averaged velocity vector, $z$ is the bed altitude and $g$ is the acceleration due to gravity. The source terms in the momentum equation are the bed slope $\nabla z$ and the bottom shear stress $\boldsymbol{\tau}_{b} / \rho$, in which $\rho$ is the water density.

The Manning's roughness coefficient, $n=0.05 \mathrm{~s} \mathrm{~m}^{-1 / 3}$, was used for evaluating the friction term in (2) by setting

$$
\frac{\boldsymbol{\tau}_{b}}{\rho}=\frac{g n^{2}}{h^{1 / 3}} \boldsymbol{u}|\boldsymbol{u}|
$$

The computational mesh was created using a 1 arc-second DEM dated 2017 from the NASA Shuttle Radar Topography Mission (SRTM) (Version 3.0 accessed at https://search. earthdata.nasa.gov), referred from now on as $z_{\mathrm{DEM}}$; this is the highest resolution seamless DEM dataset for Asia. The paleohydraulic reconstruction required a high spatial resolution (i.e. $50 \mathrm{~m}$ ) to capture with accuracy the topographic flow control exerted at the outlet of the valley pathways. Hence, a computational mesh with a cell size of about $50 \mathrm{~m}$ was created throughout the Chuja and Katun valleys where numerous giant bars developed. In the Kuray, Chuja and Uimon lakes, the computational grid was coarser with characteristic edge lengths of 100 (Kuray) and $150 \mathrm{~m}$ (Chuja). The computational mesh amounts to $2.1 \mathrm{M}$ cells and replicates real topography in the simulated region. 
Though the nature of the ice dam failure cannot be known post hoc, Herget (2005, Section 4.2.2) and Carling et al. (2010) discussed the possible ice dam failure by tunnelling or by over-topping and concluded that over-topping of the ice dam by a high lake level seems the likely failure mechanism in the Altai megaflood. We assume that thermal erosion of the ice caused rapidly widening and deepening of the sub-aerial channel in the supraglacial ice, and further discuss the hypothesis validity in Section 4 based on current numerical results, the extensions of the glacial valleys conforming the ice dam and marginal moraines (Rudoy, 2002; Reuther et al., 2006; Blomdin et al., 2016). The water flow melted progressively the ice block which resulted in the failure of the dam. To model the breach process, we modified the DEM in the ice-dam region under conditions of maximum water level, i.e. $z_{\text {ice }}=2100 \mathrm{~m}$ (Carling et al., 2011). Hence, no water could flow initially (i.e. $t=0$ ) along the Chuja valley because the ice dam retained the water in the Kuray-Chuja reservoirs. Later, a flood from the ice-dammed lakes occurred by over-topping and incision of the impounding ice mass with an incision rate $E$. Mathematically, it reads

$$
\begin{gathered}
z(\mathbf{x}, t=0)= \begin{cases}\max \left(z_{\text {ice }}, z_{\mathrm{DEM}}\right) & \text { if } \quad \mathbf{x} \in \mathbf{x}_{\text {ice }} \\
z_{\mathrm{DEM}} & \text { otherwise }\end{cases} \\
\frac{\mathrm{d} z}{\mathrm{~d} t}=-E * \max \left(\operatorname{sign}\left(z-z_{\mathrm{DEM}}\right), 0\right) \quad \text { with } \quad \mathbf{x} \in \mathbf{x}_{\text {ice }}, t>0 .
\end{gathered}
$$

Simulated flooding areas, maps of water flow depth and two-dimensional velocity vectors were obtained by solving numerically the two-dimensional unsteady shallow-water equations (1)-(3). We employed a second-order accurate HLLC approximate Riemann solver with MUSCL reconstruction and an implicit-explicit Runge-Kutta (IMEX) time integration denoted by IMEX-SSP(3,2,2)/MUSCL with MP limiter in Monnier et al. (2016). The time step in the numerical simulations was adjusted dynamically during the simulation process to satisfy the Courant-Friedrich-Lewy (CFL) stability condition.

The numerical results are presented using a planar view of the simulated variables (flow depth and velocity magnitude) to describe the dynamics of the inundation. With the main aim of visualising the circulation pattern (for instance, in the lakes), we draw streamlines at a fixed point in time from the simulated velocity vectors. The one-dimensional representation of the simulated water surface by means of a long section view along the thalweg was 

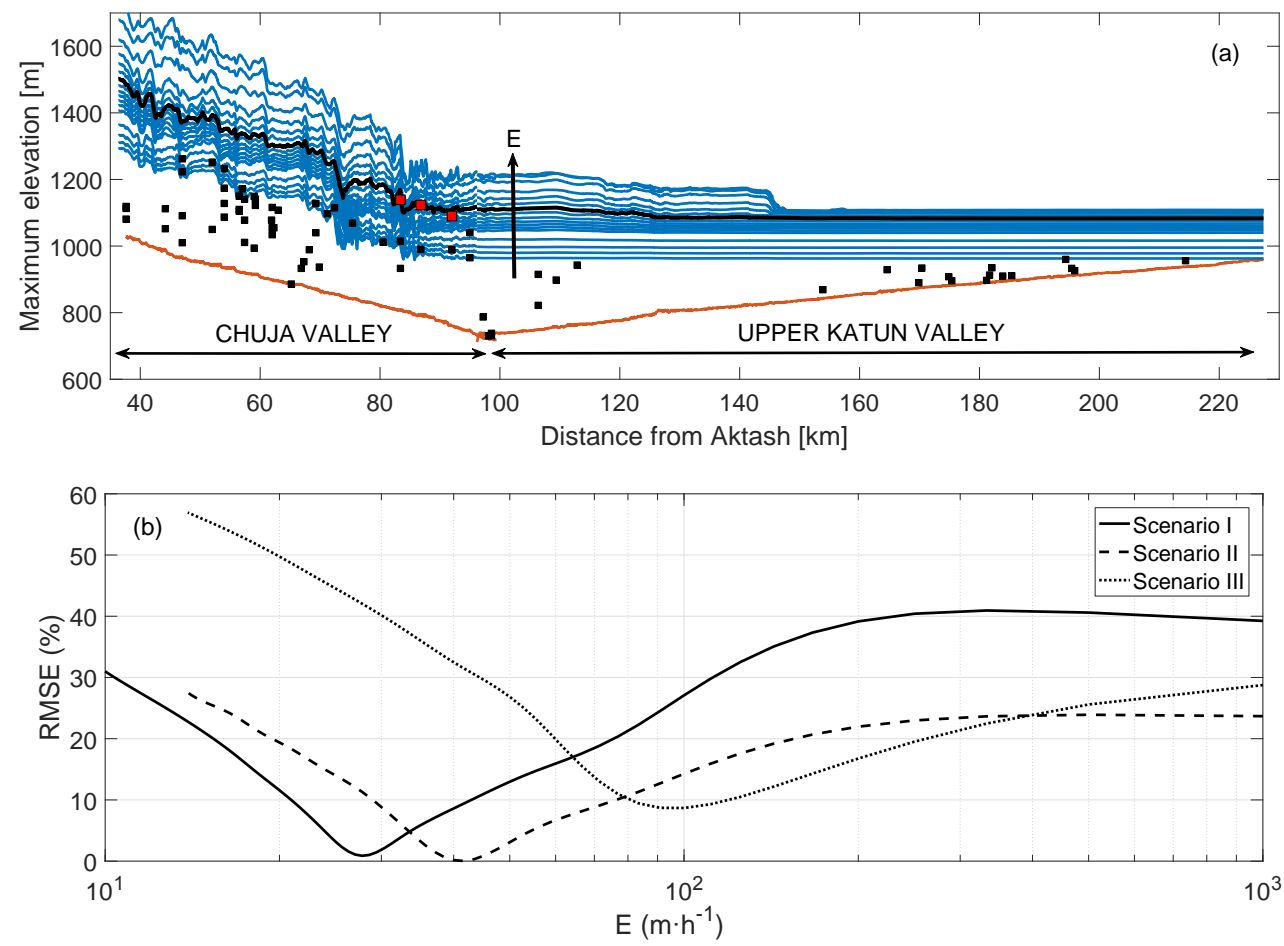

Fig. 3: (a) Maximum elevation downstream of the ice dam in scenario I for the simulated values of $10 \leq$ $E \leq 10^{3} \mathrm{~m} \cdot \mathrm{h}^{-1}$. The red squares highlight the run-up sediments that served as HWM-PSIs to infer the optimal value of $E=28 \mathrm{~m} \cdot \mathrm{h}^{-1}$. The black solid line depicts the maximum elevation for the optimal solution. (b) RMSE for the three simulated scenarios.

crucial to gain insight into the dynamics of the intricate megaflood. Also considered are the dimensionless parameters Shields and Froude numbers. Both instantaneous and maximum values in time are finally employed to describe the formation of megaflood-scale bedforms.

\subsection{Determination of the ice incision rate}

We modelled two breaching scenarios for over-topping, ranging from a partial breach to a complete collapse of the ice dam. We also considered two initial conditions of the lakes for the complete collapse, including the possibility that only the Kuray basin contained water; the Chuja basin being dry. The resulting scenarios were as follow:

- Scenario I: both Kuray and Chuja reservoirs were initially full when the ice dam breached completely with a constant incision rate $E$. Masses of water discharged along the northern and southern channels of the ice dam. 

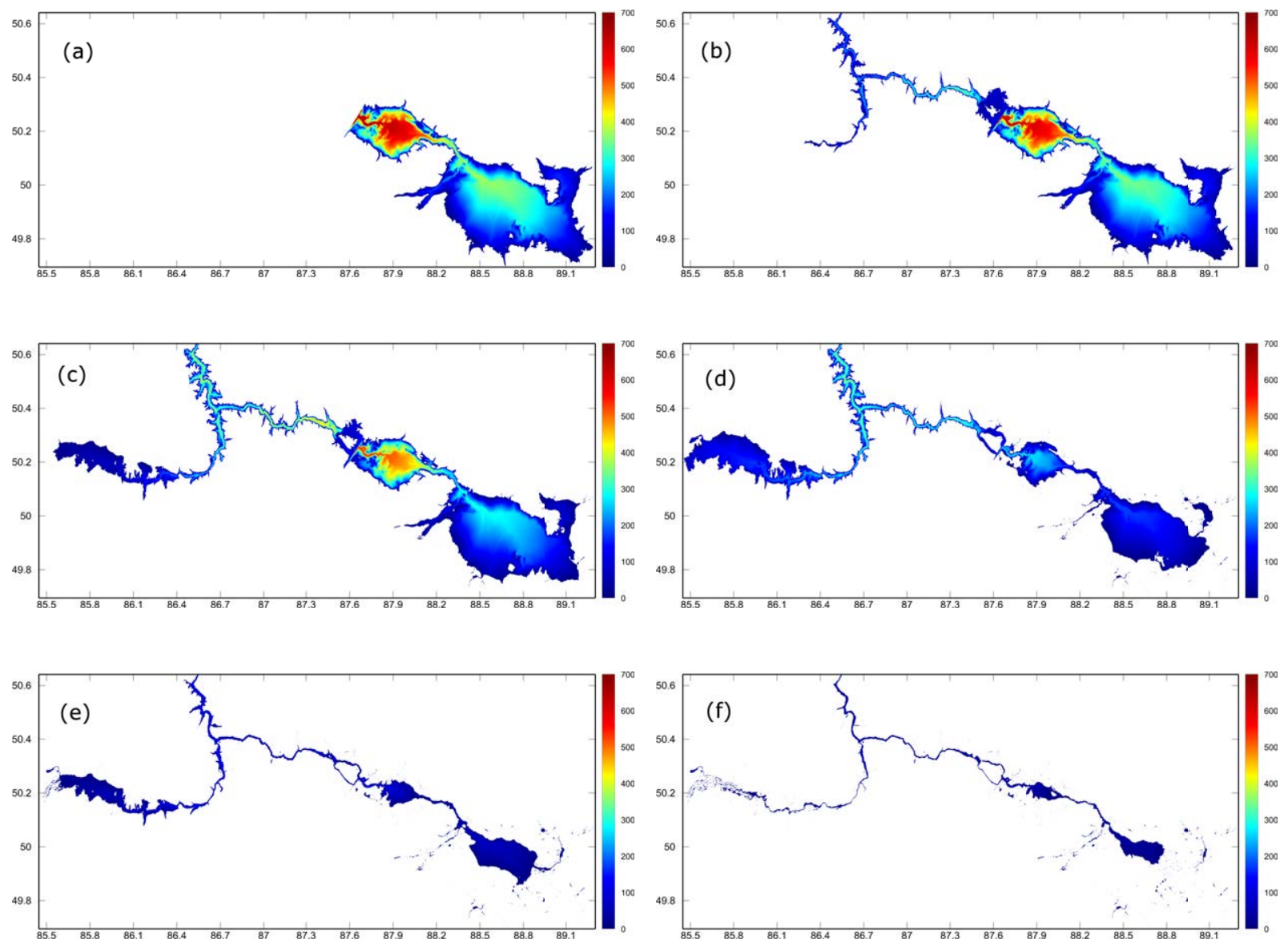

Fig. 4: Snapshots of flow depth at several instants of time for the optimal value of $E$ with full breach of the ice dam. (a) Initial condition in the Kuray and Chuja lakes at $t=0 \mathrm{~h}$. (b) Propagation of the flood along the Chuja valley at $t=5 \mathrm{~h}$, when the flow bifurcated at the confluence with the Katun valley. (c) Start of filling of the Uimon lake at $t=10 \mathrm{~h}$. (d) Maximum filling of the Uimon lake at $t=20 \mathrm{~h}$. (e) Partial drainage of the Uimon lake at $t=40 \mathrm{~h}$. (f) Nearly empty lakes at $t=60 \mathrm{~h}$. Northings and eastings in degrees. See also Supplementary video 1.

- Scenario II: similar to the scenario I but with a partial breach of the dam. The northern channel (near Aktash) remained ice-filled to block that outlet. Water could flow only after overtopping and deepening the sub-aerial channel in the southern reach.

- Scenario III: breach process as for scenario I but considering that only the Kuray lake was full at $t=0$.

Taking into account that the confined Chuja valley is the preferred setting to perform the paleohydraulic reconstruction, because an increase in flood discharge results in a large 
increase in the stage (Baker, 1987), we set $E$ as an unknown constant to be determined by best fitting the elevations of the high-water mark PSIs in the Chuja valley. For each scenario, we proceeded as follows:

1. First, we fixed a value of $E$ and run the transient numerical simulation solving the depth $h(\mathbf{x}, t)$ and velocity $\boldsymbol{u}(\mathbf{x}, t)$ at every point in space and time;

2. The second step consisted of computing the maximum value in time for each position $\mathbf{x}$, which is denoted as $h_{\max }(\mathbf{x})$. The maximum simulated water surface elevation is then given by $z_{\max }(\mathbf{x}) \equiv h_{\max }(\mathbf{x})+z_{\mathrm{DEM}}(\mathbf{x})$.

3. Subsequently, we defined the relative root mean square error (RMSE) as

$$
\mathrm{RMSE}=\sqrt{\sum_{i=1, n} \frac{1}{n}\left[\frac{z_{\mathrm{max}}\left(\mathbf{x}_{i}\right)-z_{\mathrm{PSI}}\left(\mathbf{x}_{i}\right)}{z_{\mathrm{PSI}}\left(\mathbf{x}_{i}\right)-z_{\text {thalweg }}\left(\mathbf{x}_{i}\right)}\right]^{2}}
$$

where $z_{\mathrm{PSI}}$ denotes the altitude of the HWM-PSI and $z_{\text {thalweg }}$ is the thalweg elevation of the cross section containing the PSI.

In the evaluation of (6), we used $n=3$ that corresponds with the three HWM-PSIs highlighted with a red square in Fig. 3. They represent the highest run-up sediments in Chuja valley.

4. Finally, we repeated the process by changing the value of $E$ and constructed the curve $\operatorname{RMSE}(E)$. The optimum value of $E$ corresponds with the minimum RMSE.

To illustrate how we applied the above procedure, Fig. 3 shows a long section view of the maximum water elevation simulated for scenario I, and the corresponding RMSE, as $E$ increases from 10 to $10^{3} \mathrm{~m} \cdot \mathrm{h}^{-1}$. If the breach process is too slow $\left(E \ll 28 \mathrm{~m} \cdot \mathrm{h}^{-1}\right)$, then the run-up sediments are not inundated, and the corresponding RMSE is too high. As $E$ monotonously increases, $z_{\max }$ increases to inundate all the PSIs for $E_{I}=28 \mathrm{~m} \cdot \mathrm{h}^{-1}$ (optimal solution). Hence, the RMSE vanishes. To conclude, if the incision rate increases further (i.e. $E>E_{I}$ ), then the error rises again achieving the maximum constant value RMSE $=40 \%$ for $E>300 \mathrm{~m} \cdot \mathrm{h}^{-1}$.

For completeness, we included in Fig. 3b the error curves of scenarios II and III. We found that the partial breach scenario (case II) was as plausible as the full breach scenario (case I) because the minimum value of RMSE vanished for a given value of the incision rate (i.e. 

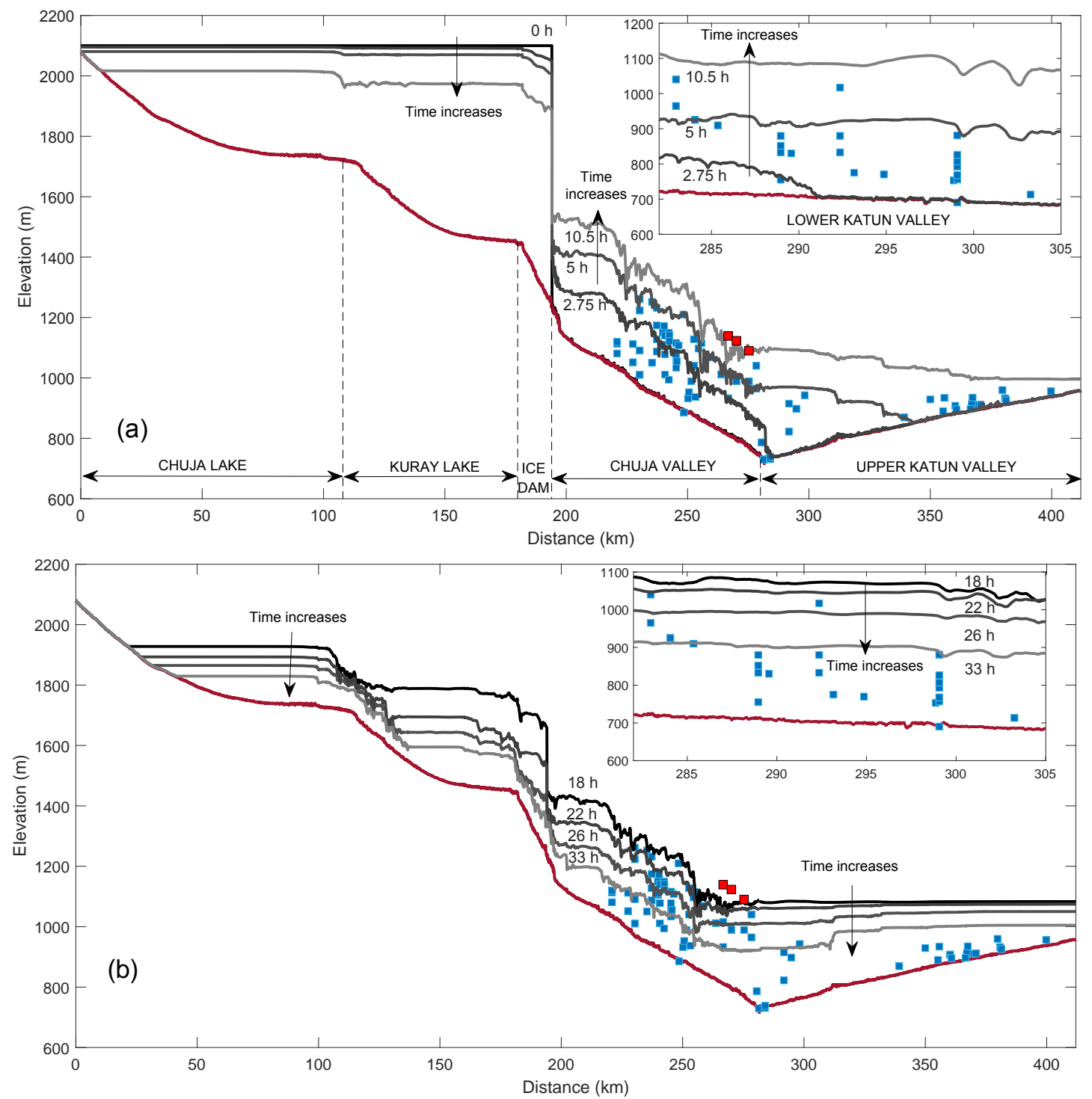

Fig. 5: Long view section of water surface at several instants of time in the breach scenario I: (a) $0,2.75,5$ and $10.5 \mathrm{~h}$; (b) 18, 22, 26 and $33 \mathrm{~h}$. The arrow indicates the time direction. The PSIs (blue squares) and HWM-PSIs (red squares) correspond with those in Fig. 3a. The inset represents the longitudinal profile of the simulated elevation along the Katun stretch downstream of the confluence with Chuja valley at the same sets of points in time. The red line is the thalweg. See a didactic animation in Supplementary video 2.

$\left.E_{I I}=42 \mathrm{~m} \cdot \mathrm{h}^{-1}\right)$. That is, the highest PSI was inundated in both scenarios I-II. However, if we set as an initial condition that Kuray lake was filled and Chuja was empty (scenario III), then the error never vanishes because the highest PSI is not inundated during the megaflood. Hence, in the remaining of the paper, we only report on the results of scenarios I and II. 


\section{Results}

\subsection{Dynamics of the megaflood in Chuja and Katun valleys}

The sequence of maps of flow depth (Fig. 4) and long section views of water surface altitudes (Fig. 5) depict the different stages that developed in the Altai megaflood. Initially, see Fig. 4a and black solid line in Fig. 5a, the water surface in Kuray and Chuja lakes was at the level $z_{\text {ice }}=2100 \mathrm{~m}$ with maximum lake depths of 685 and $383 \mathrm{~m}$, respectively. The ice dam, which was at the same level, retained a water volume of $564 \mathrm{~km}^{3}$ in the reservoirs. The erosion of the crest of the ice dam occurred due to over-topping, and the flood commenced. The integration of (5) yields the maximum elevation of the ice block as a function of time, i.e. $z(t)=\max \left(z_{\text {DEM }}, z_{\text {ice }}-E t\right)$.

In less than $2.5 \mathrm{~h}$ (Fig. 5a), the flood inundated the Chuja valley downstream of the dam and reached the confluence with Katun valley. Subsequently, a portion of the water volume propagated in the downstream direction of the Katun River, but the remaining volume moved upstream along the Upper Katun River, as shown by the solution at $t=5 \mathrm{~h}$ in Figs. $4 \mathrm{c}$ and 5a. As a consequence, a third temporary lake (referred to as Uimon lake) started to be filled. The flow depth achieved the maximum value in time along Chuja valley at $10.5 \leq t \leq 11 \mathrm{~h}$ (panel 4d and light gray line in Fig. 5a), when the discharge achieved the peak value 10.5 $\mathrm{M} \mathrm{m}^{3} \cdot \mathrm{s}^{-1}$ and the Kuray-Chuja lakes had drained $45 \%$ of the initial volume (Fig. 6).

Interestingly, Fig. 6a indicates that the hydrographs at the inlet (black line) and outlet (blue line) of the Chuja valley nearly overlap during the whole drainage of the lakes. We can then state that the streamflow was uniform along the Chuja stretch independently of the instant time and the magnitude of the discharge, though it varied slowly on time. This behaviour is referred to as a kinematic wave, and has been used routinely to propagate flood waves in long rivers (Lighthill and Whitham, 1955; Singh, 2002; Bohorquez, 2010). The smooth variation of the discharge during the rising and recession limbs at the Chuja valley relates to the progressive incision of the ice-dam (i.e. $20<E<50 \mathrm{~m} \cdot \mathrm{h}^{-1}$ ). Conversely, the sudden dambreak scenario as well as the fast collapse of the dam (i.e. $E>200 \mathrm{~m} \cdot \mathrm{h}^{-1}$ ) exhibit an instantaneous rising limb dominated by an exponential falling limb that attenuates downstream (e.g. Bohorquez et al., 2016). The instantaneous ice-dam failure is however unreliable in the Altai megaflood because the flow depths are too deep regarding the paleostage 

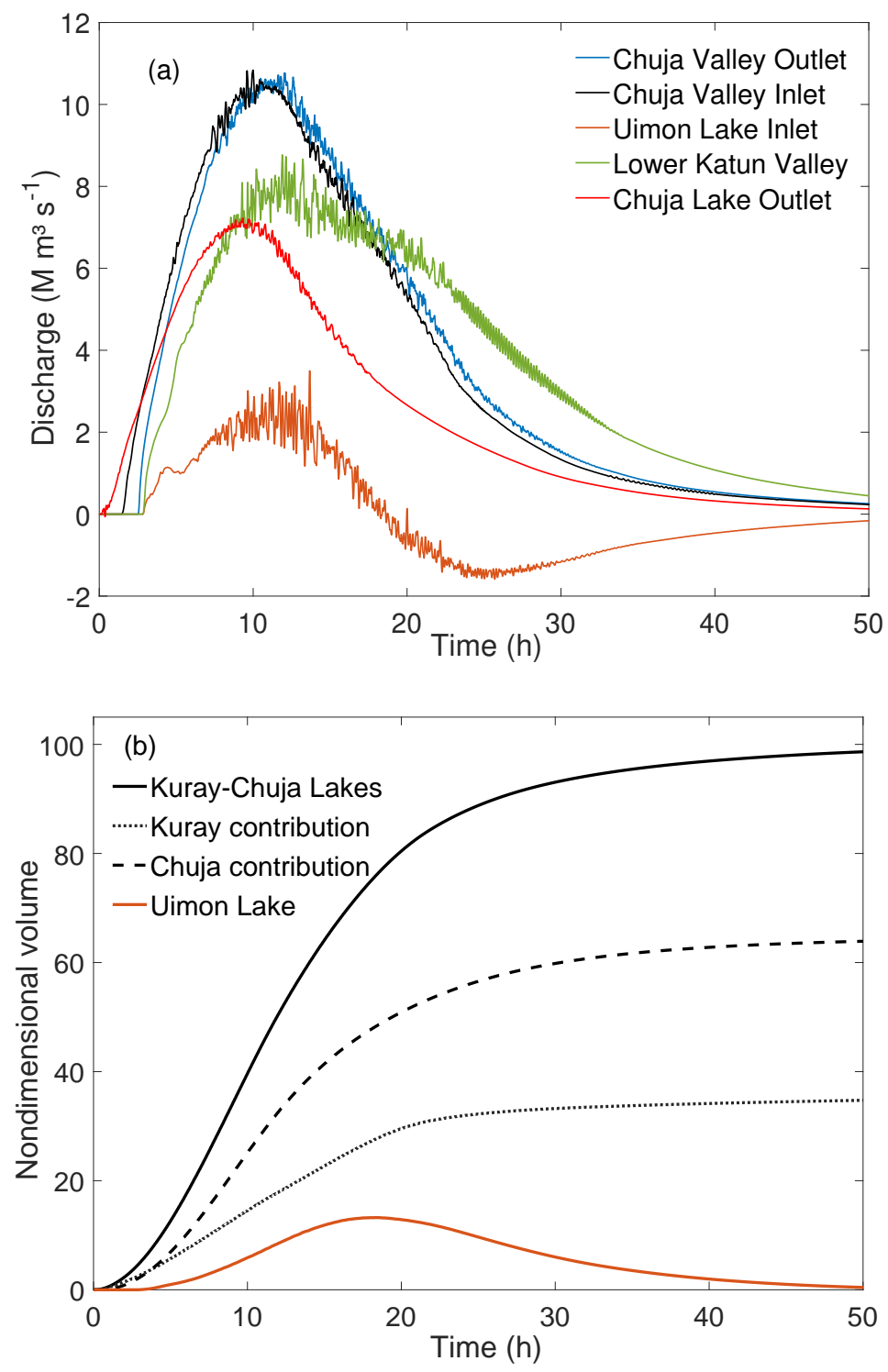

Fig. 6: (a) Simulated discharges in various cross-sections of the drainage network as indicated in the legend. (b) The solid line in black shows the volume drained out of Kuray-Chuja lakes with respect to the initial volume in percentage. The dotted and dashed lines are the Kuray and Chuja contributions. The portion of the volume stored in Uimon lake is shown in orange.

indicators (recall Fig. 3a).

Crucial phenomena developed at the time of peak flow and maximum depth. First, the three highest PSIs (run-up sediments) were inundated (see red squares and light grey line in Fig. 5a). Second, the surface slope was sharp downstream of the first run-up sediment, at a distance of $266 \mathrm{~km}$, and the water level oscillated along $10 \mathrm{~km}$ further downstream, 

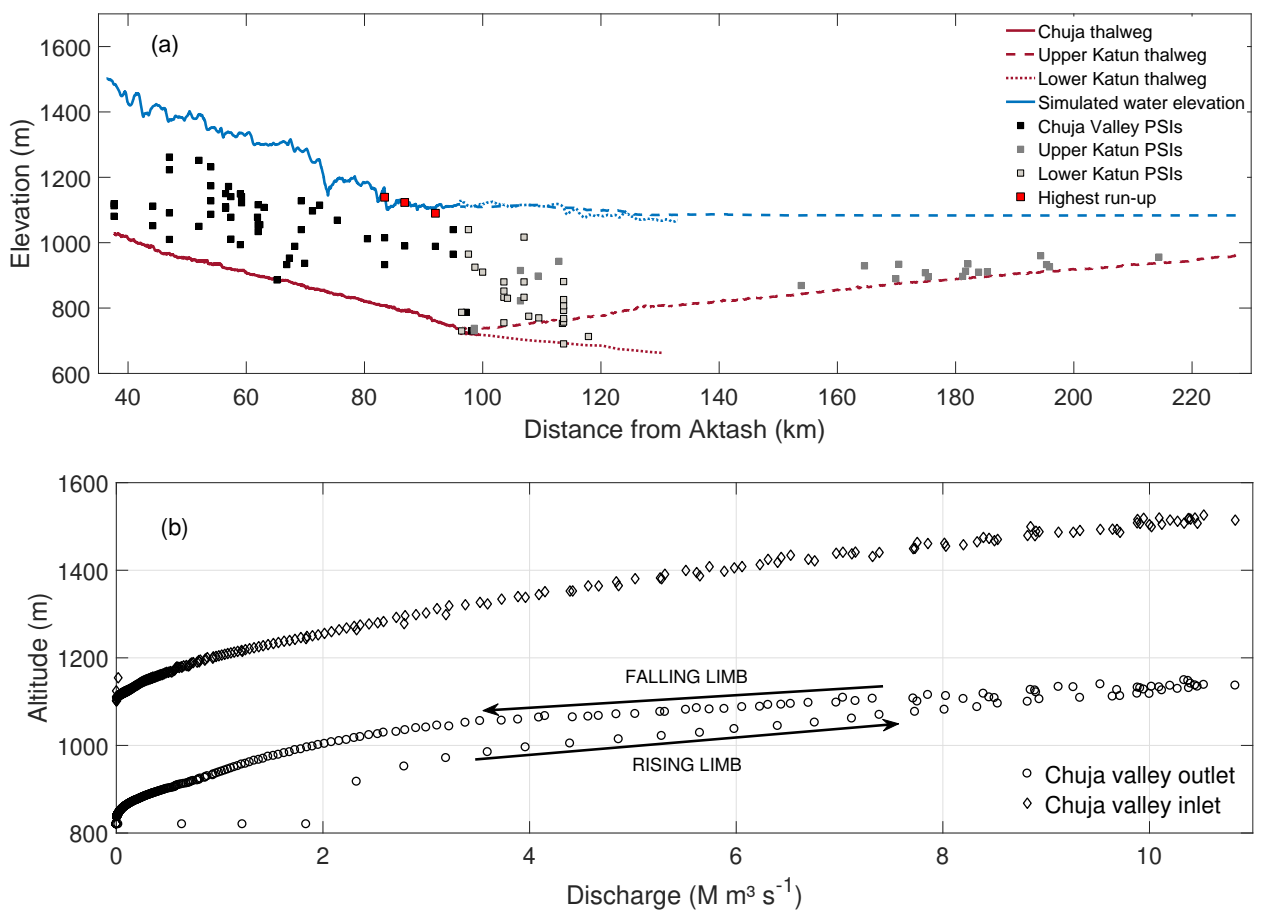

Fig. 7: (a) Maximum elevation downstream of the ice dam in scenario I for the optimum value $E=28 \mathrm{~m} \cdot \mathrm{h}^{-1}$. (b) Rating curve at the inlet and outlet of Chuja valley showing the counter-clockwise backwater effect from Uimon lake.

allowing the inundation of the other two HWM-PSIs. The analysis of the Froude number (see Supplementary video 3),

$$
\mathscr{F} r=\frac{|\boldsymbol{u}|}{\sqrt{g h}}
$$

shows oscillations around criticality on the opposite side of the run-up (near Point 32 in Table A1 by Herget, 2005). The flow depth referred to the thalweg was as deep as $330 \mathrm{~m}$ at these locations. Further upstream, a flow deeper than $386 \mathrm{~m}$ occurred in subcritical regime, with several transitions from supercritical to subcritical regime, and vice-versa, along the reach. A couple of two-dimensional hydraulic jumps were present in the Chuja valley, but their exact locations depended on time because of the transient state of the megaflood. The oscillations of the hydrographs in Fig. 6a were indeed provoked by the displacement of the hydraulic jumps (see Supplementary video 3), which was perceived in the whole drainage network.

The flood wave propagated upstream in the Katun River and filled Uimon Basin for 18 hours (see the positive value of the inlet discharge at Uimon in Fig. 6a), at the same time 
that draining proceeded down the Lower Katun River. An approximation to the maximum extension of Uimon lake is given in Fig. $4 \mathrm{~d}$ at $t \approx 20 \mathrm{~h}$. At that time, the stored water volume was a maximum (see Fig. 6b) with a capacity of $13 \%$ of the initial volume of the Kuray-Chuja lakes. Later, the water discharge at Uimon became negative, and water flowed naturally in the downstream direction along the Katun River. When $t>18 \mathrm{~h}$, the inundated area decreased in Uimon (see, for instance, panels 4 e-f at $40 \leq t \leq 60 \mathrm{~h}$ ). Indeed, Fig. 5b depicts the decreasing lake level for $t>18 \mathrm{~h}$, as well as the backwater effects in the stretch of Chuja valley with the HWM-PSIs (note the break-in surface slope). Uimon lake influenced the dynamics of the megaflood where the highest run-up sediments exist. To conclude, peak discharges in Uimon during the filling and emptying stages were about 3 and $1.5 \mathrm{M} \mathrm{m} \cdot \mathrm{s}^{-1}$, respectively.

At this point, it is convenient to comment on the maximum water altitudes simulated in Chuja, Upper Katun and Lower Katun valleys, which are plotted in Fig. 7a. The maximum elevation of the simulated water surface (coloured in blue) represents the involute of the instantaneous curves described in Fig. 5. The only way to obtain the graph is to run the unsteady numerical simulation and compute the maximum in time at each specific location during the simulation process. At distances farther than $80 \mathrm{~km}$ from Aktash, the free surface remained nearly parallel to the thalweg with a mean slope of 0.4 degree. The maximum water level varies in the narrow range of 1070-1115 m along $30 \mathrm{~km}$ and $120 \mathrm{~km}$ in the Lower and the Upper Katun valley, respectively, where the water surface is nearly horizontal. Note that the maximum altitude of the simulated water surface reached the highest run-up sediments (red squares), minimising the RMSE (6). This constraint constitutes the basis of our paleohydraulic reconstruction method (recall Section 2.2). Note that the level of the run-up sediments is nearly the same as the water elevation in Uimon lake, which plays a key role in our paleohydraulic reconstruction.

The backwater effect at the confluence of the Chuja and Katun rivers is evident in the rating curve of the Chuja reach outlet, as depicted with solid circles in Fig. 7b. At a given flow discharge, the elevation of the water surface during the falling limb was higher than the rising limb. For instance, for $4 \mathrm{M} \mathrm{m}^{3} \cdot \mathrm{s}^{-1}$, the water elevation was $1061 \mathrm{~m}(996 \mathrm{~m})$ in the falling (rising) limb, which amounts to a difference of $65 \mathrm{~m}$ in depth. The difference decreases 
as the streamflow increases and is negligible at peak discharge (i.e. $10.8 \mathrm{M} \mathrm{m}^{3} \cdot \mathrm{s}^{-1}$ ) with an elevation of $1150 \mathrm{~m}$. Conversely, at the entrance of the Chuja stretch (60 km upstream), the rating curve defines a one-to-one relationship between streamflow and water elevation. The unsteady, two-dimensional shallow-water equations properly capture all these phenomena.

\subsection{Drainage process of Kuray-Chuja lake}

The computed temporal evolution of the falling flow depths in the lakes is reported in Fig. 8a. The maximum initial depth in Kuray $(680 \mathrm{~m})$ is greater than in Chuja (383 m), due to the altitude of the basin thalwegs falling towards the ice-dam. However, the initial discrepancy in depth is reduced rapidly with time. Notice that the released lake volumes (Fig. 6b) increase rapidly with time and, subsequently, although there is some deep, localized, residual ponding (40 m depth) at a late time $(t>100 \mathrm{~h})$, the residual volume is negligible with respect to the initial one. Indeed, the greater part of the lake volume (95\% of the initial volume) is evacuated by $33.8 \mathrm{~h}$.

During the filling stage of the Chuja valley, i.e. $t \leq 11 \mathrm{~h}$, the water level decreased from 2100 to $1974 \mathrm{~m}$ in the Kuray lake, and from 2100 to $2016 \mathrm{~m}$ in the Chuja basin (see Fig. 5a). The water surface remained nearly flat in both lakes, but their levels slightly differed due to the head losses in the valley pathway from Chuja to Kuray. The velocity in the Chuja basin was generally relatively low (i.e. $5 \mathrm{~m} \cdot \mathrm{s}^{-1}$ ) but reached approximately $46 \mathrm{~m} \cdot \mathrm{s}^{-1}$ at the entrance to the constricted valley near Chagan-Uzun (Fig. 8b), see Supplementary video 4. At the outlet of Chuja lake, the reconstructed hydrograph (see red line in Fig. 6a) exhibits a significant peak value of $7 \mathrm{M} \mathrm{m}^{3} \cdot \mathrm{s}^{-1}$ at $t=9.5 \mathrm{~h}$, when Kuray lake discharged $10 \mathrm{M} \mathrm{m}^{3} \cdot \mathrm{s}^{-1}$ downstream of the ice dam. The throttling effect of the constriction between the Chuja and Kuray basins constrained the evacuation of water from the Chuja Basin. The Chuja lake refilled the Kuray basin not only at this period of time but during the whole drainage process.

In contrast to the Chuja basin, a complex circulation characterized with multiple megaeddies occurred in the Kuray Lake. The Chuja basin water exited as a jet-flow into the Kuray basin via the narrow conjoining valley, as shown by the streamlines and contours of velocity magnitude in Fig. 9a at $t=6 \mathrm{~h}$. At that time, we found a local maximum of 

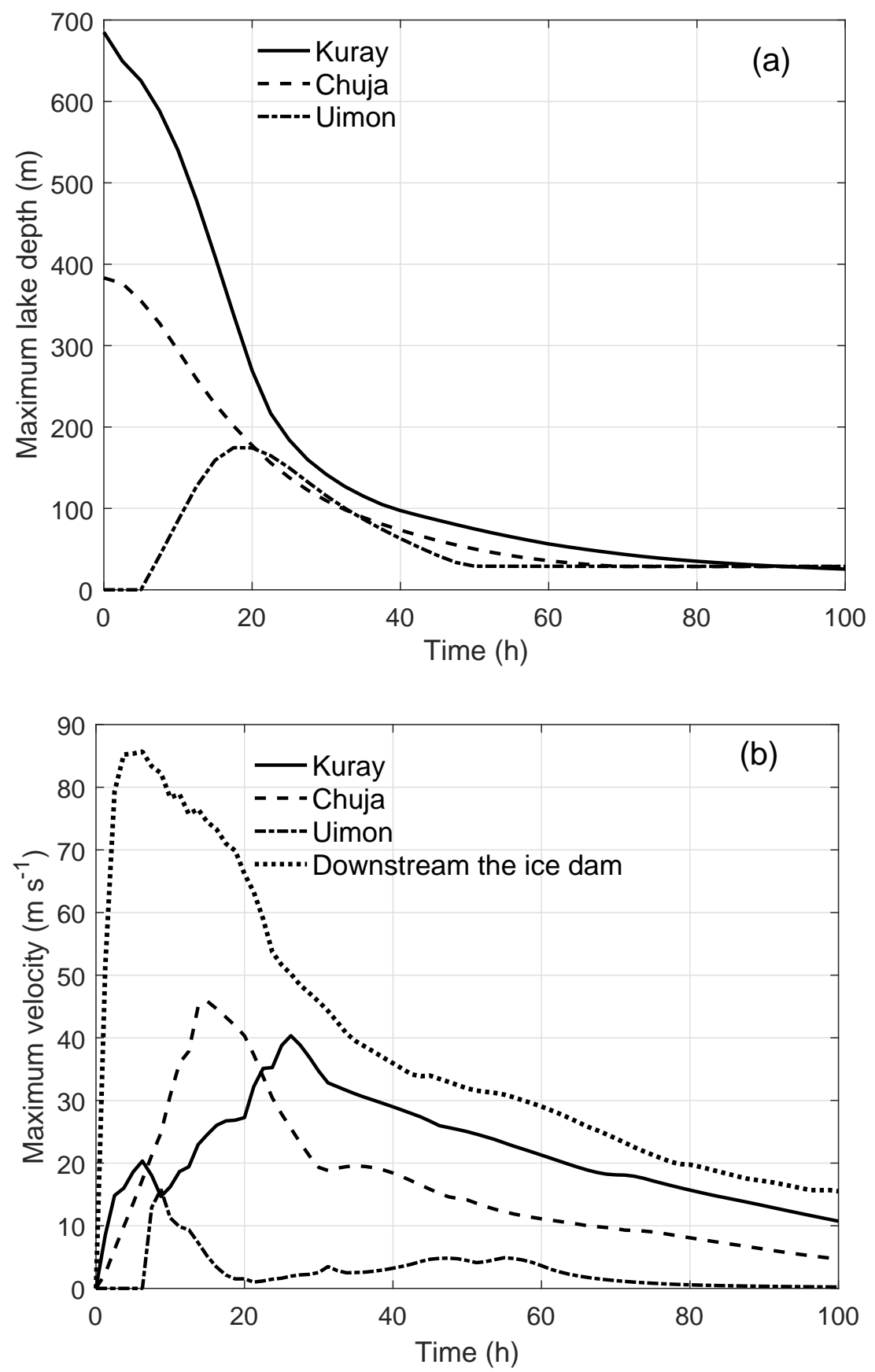

Fig. 8: (a) Maximum depth in Kuray (continuous line), Chuja (dashed line) and Uimon (dash-dotted line) lakes. (b) Maximum velocity in Kuray (continuous line), Chuja (dashed line) and Uimon (dash-dotted line) lakes, and downstream the ice dam (dotted line).

$20 \mathrm{~m} \cdot \mathrm{s}^{-1}$ (Fig. 8b). The high velocity is maintained along the pathway and decreases when discharging into the Kuray basin due to the abrupt flow expansion. In the southern region 

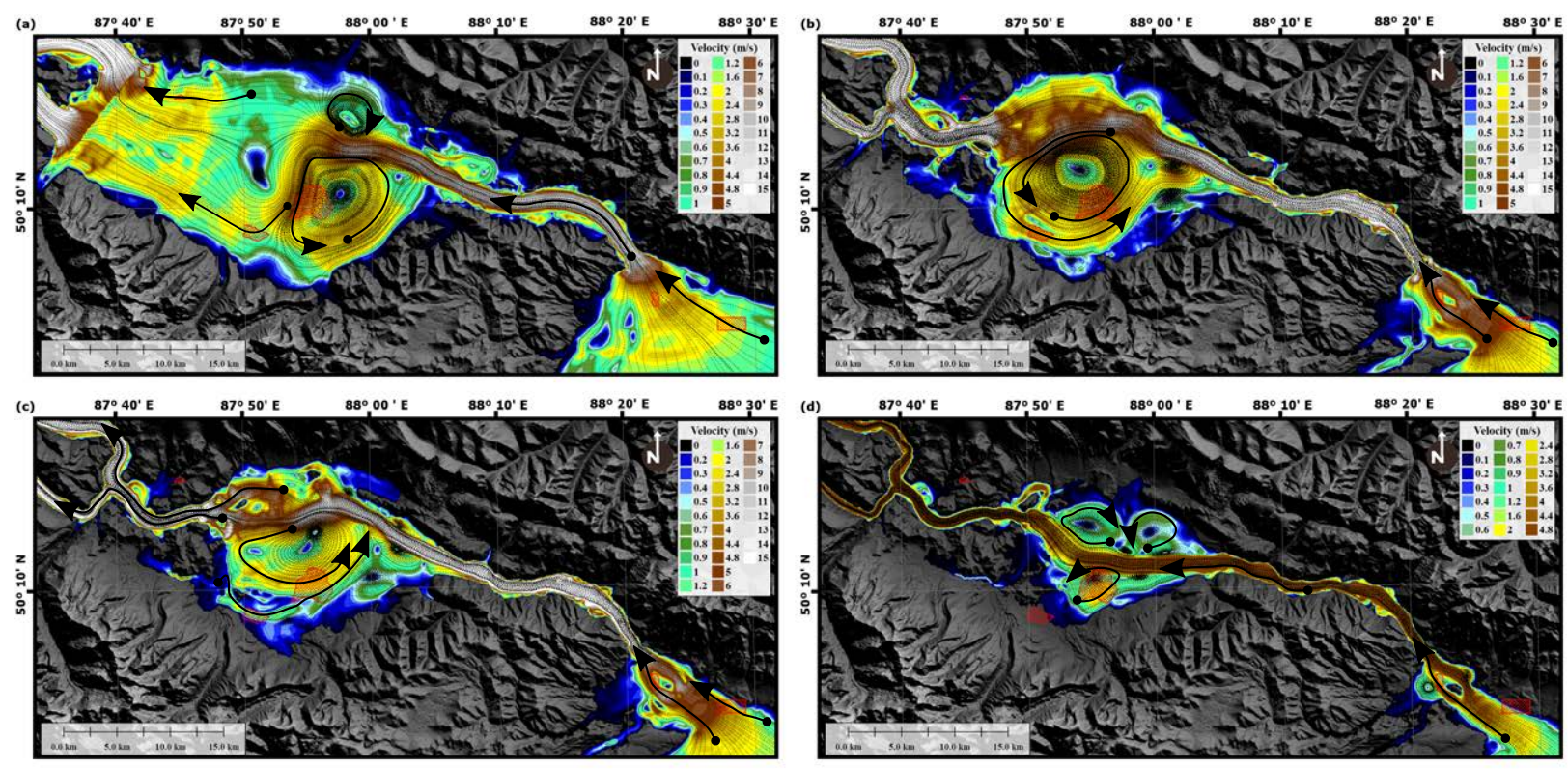

Fig. 9: Snapshots of streamlines (dotted lines) and contours of velocity magnitude $\left(\mathrm{m} \cdot \mathrm{s}^{-1}\right)$ in Kuray basin at several instants of time for the optimal value of $E$ with full breach of the ice dam: (a) 6, (b) 17.5 , (c) 21.5 and (d) $31 \mathrm{~h}$. The areas in red and the arrowed lines highlight, respectively, the position of the dune fields and the main flow directions nearby.

of the jet-flow a mega-eddy develops, which was responsible for the growth of the Kuray gravel-dune field. The flow decelerates rapidly as it leaves the constriction. Then, the flow increases once again close to the exit from the Kuray basin near the former ice-dam.

The flow regime in the Kuray basin is undoubtedly two-dimensional and unsteady. As time proceeds, the wetted area of the lake decreases, velocities as high as $40 \mathrm{~m} \cdot \mathrm{s}^{-1}$ develop (Fig. 8b), and the vortex size and position varies due to the refilling of the lake, see panels 9b$\mathrm{d}$ for $t=17.5,21.5$ and $31 \mathrm{~h}$. The high velocities in the narrow conjoining valley, and the corresponding head losses induce larger differences in the lake levels with time, which are visible in Fig. 5b and amount to 141, 198, 222 and $234 \mathrm{~m}$ at $t=18,22,26$ and $33 \mathrm{~h}$. We shall see that the high velocities in the period $5 \leq t \leq 22 \mathrm{~h}$ sustained the formation of the Kuray dune field for 17 hours.

The results serve to quantify the maximum flow depth, velocity, and the Shields and Froude number during the lakes drainage. To evaluate the Shields parameter,

$$
S h=\frac{\left|\boldsymbol{\tau}_{b}\right|}{\rho(s-1) g d},
$$



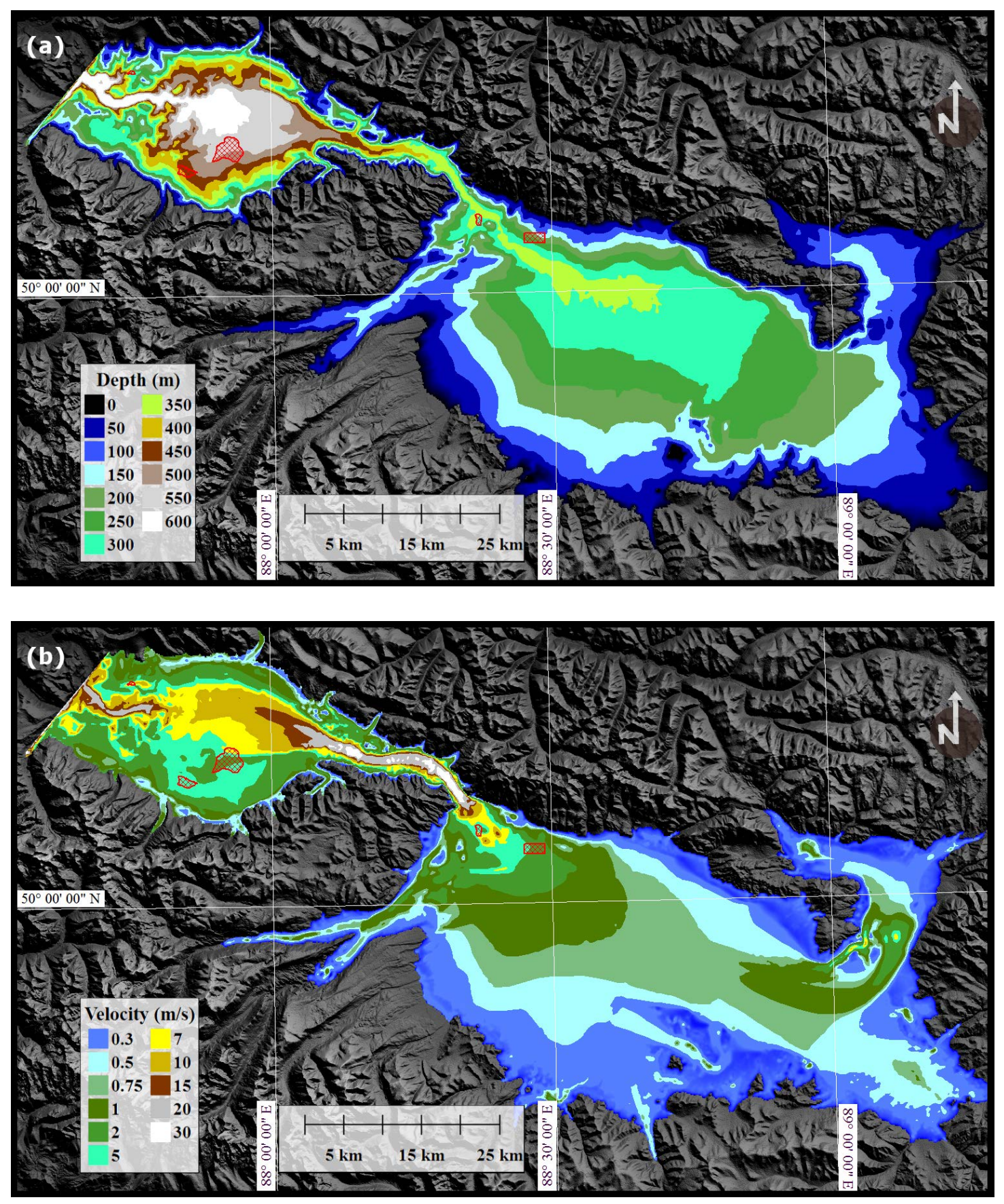

Fig. 10: Maps of maximum values in Kuray and Chuja lakes during the $200 \mathrm{~h}$ of the numerical simulation: (a) water depth and (b) velocity. Supplementary videos 1 and 3 show an animation of the instantaneous values. The areas in red highlight the position of the dune fields.

we set the constant relative density mismatch between fluid and sediment $s=2.65$ for quartz in water and the mean particle diameter to $d=0.035 \mathrm{~m}$ (Carling, 1996a).

The basic flow data are illustrated in Figs. 10 and 11. The maximum flow depth in 

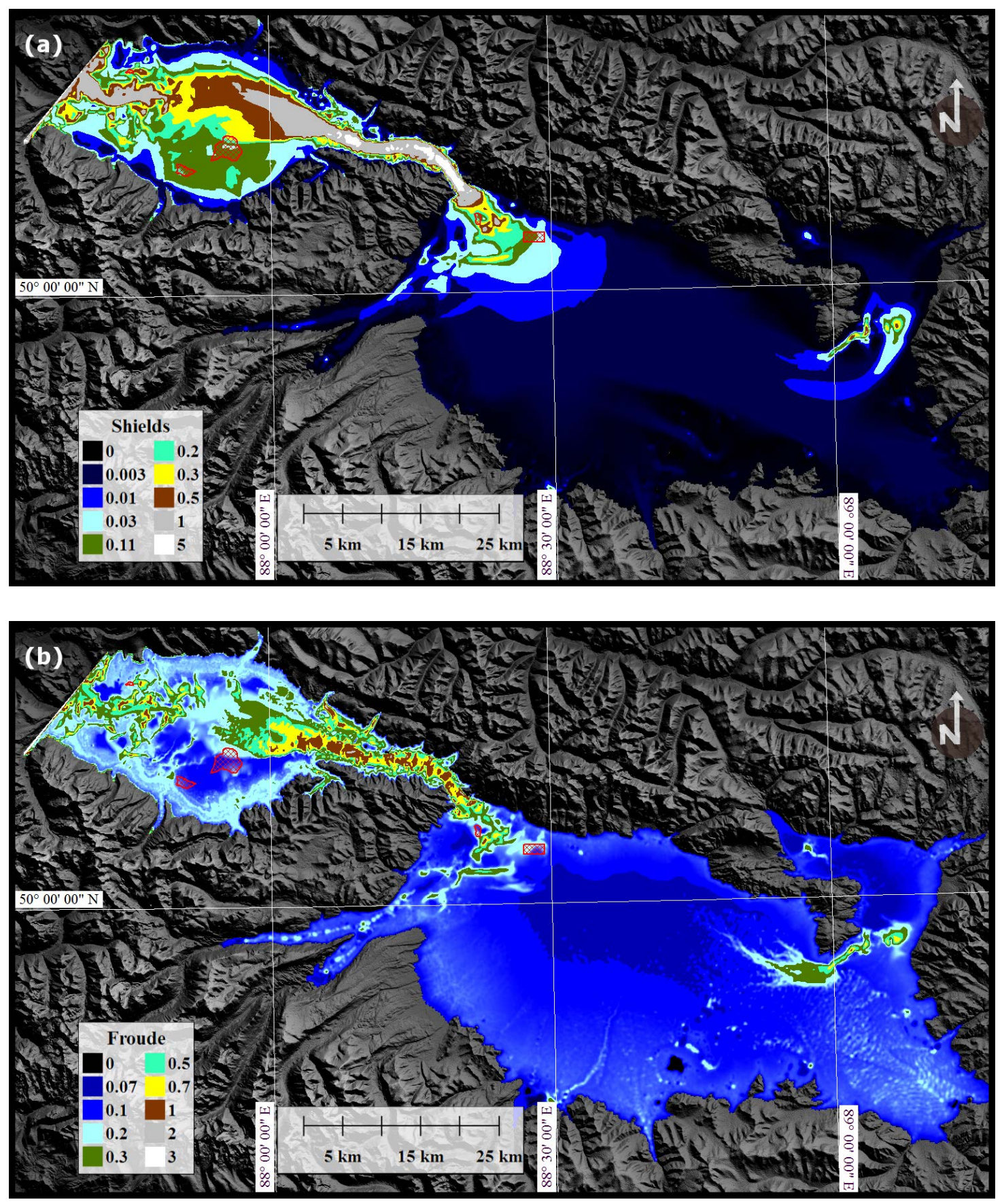

Fig. 11: Maps of maximum values in Kuray and Chuja lakes during the $200 \mathrm{~h}$ of the numerical simulation: (a) Shields and (b) Froude number. Supplementary videos 4-5 show an animation of the instantaneous values. The areas in red highlight the position of the dune fields.

Fig. 10a corresponds to the initial elevation of $2100 \mathrm{~m}$, and the intricate shapes of the contour levels are provoked by the lakes' bathymetry. Notably, the velocity in the Chuja basin was 

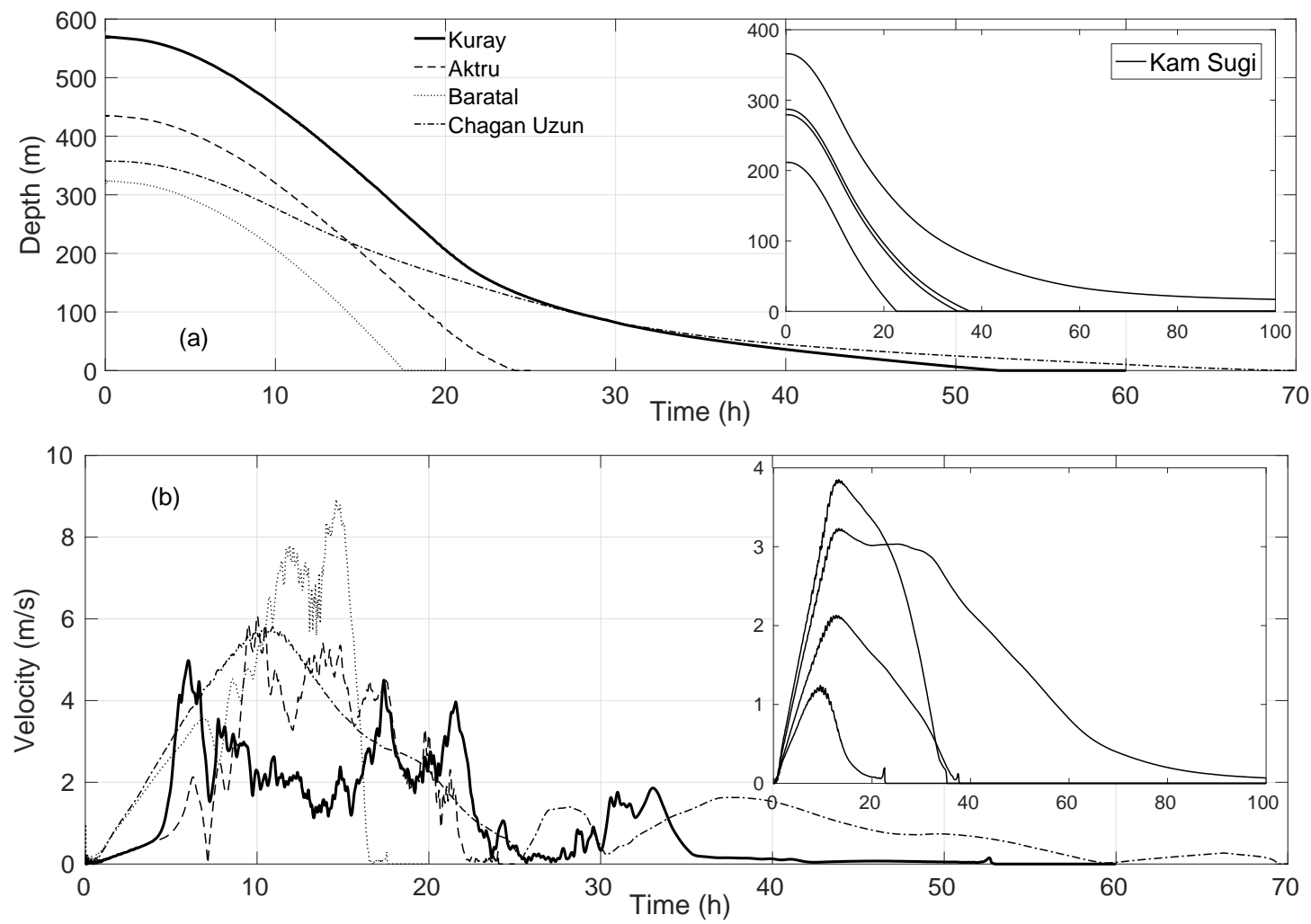

Fig. 12: (a) Flow depth and (b) velocity magnitude as a function of time in the dune fields of Kuray-Chuja lakes. The four curves in Kam Sugi (inset) correspond with the four corners of the boxed area in Chuja lake (Fig. 1). The locations of Kuray, Aktru, Baratal and Chagan Uzun dune fields are also marked in Fig. 1.

generally relatively low except at the entrance to the constricted valley near Chagan-Uzun (Fig. 10b), as explained above. The low velocities induced a Shields parameter below the threshold for sediment motion $S h_{c r}=0.03$ in most of the Chuja basin (dark blue region in Fig. 11a), which explains the absence of bedforms in that region. Also, at the specific locations where alluvial bedforms exist to this day, the erosion criterion $S h>S h_{c r}$ is satisfied, as explained in the next section. The Froude number at the locations of interest, see Fig. 11b, was $\mathscr{F} r \leq 0.4$ in agreement with the dune criterion $\mathscr{F} r \lesssim 0.7$ (Carling and Shvidchenko, 2002; Bohorquez et al., 2019).

\subsection{The formation of gravel-dune fields}

The catastrophic draining of Kuray and Chuja lakes in the Late Pleistocene formed large fields of giant gravel dunes in Kuray and Chuja basins (Fig. 1a). We selected here for the analysis of the hydrodynamic processes the positions referred to as Kuray, Aktru, Baratal, 

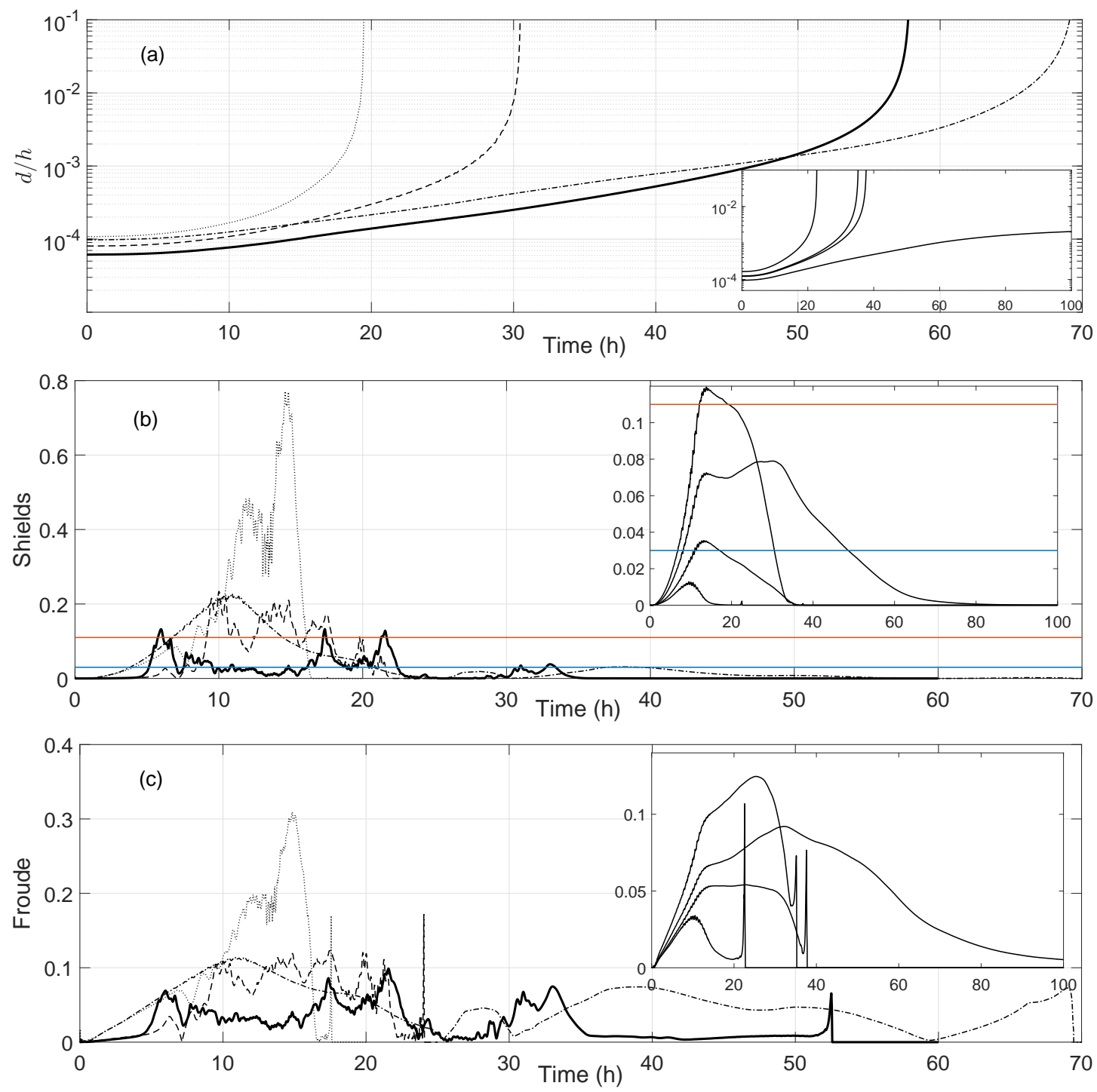

Fig. 13: (a) Nondimensional grain roughness relative to flow depth, i.e. inverse of the relative submergence, (b) Shields parameter and (c) Froude number as a function of time corresponding with the flow depth and velocity in the Kuray, Aktru, Baratal and Chagan Uzun bedform fields of the Kuray-Chuja lakes (as Fig. 12). The four curves in the inset correspond with the four corners of the Kam Sugi area in the Chuja lake (Fig. 1).

Chagan Uzun and Kam Sugi. Carling (1996a), Carling et al. (2002) and Herget (2005) described in detailed the morphology and sedimentology of such large bedforms. To verify the accuracy of the current paleohydraulic reconstruction of Altai megaflood, we check in this section the hydraulic conditions close-up to form giant gravel dunes.

We monitored the flow depth and velocity at several points over each location. Independently of the position selected in Kuray, Aktru, Baratal and Chagan Uzun, the hydraulics 
variables remained uniform. Hence, the simulated depth and velocity magnitude shown in Figs. 12a-b are representative of each dunefield during the lake draining. In the fifth region, i.e. Kam Sugi, both the depth and velocity varied significantly due to the complex bathymetry. For clarity, we included as an inset of Fig. 12 the data for each corner of the boxed area in the Chuja basin (Fig. 1a). Note the variability of the flow depth and velocity across the nonuniform flow field. To draw an interpretation of the corresponding bedforms, it is convenient to make the simulated variable dimensionless. Carling and Shvidchenko (2002) originally propose a bedform stability diagram based on the Froude, $\mathscr{F} r$, and relative submergence, $h / d$. Bohorquez et al. (2019) presented a shallow water theory for the formation of megaflood scale dunes and antidunes also using the Froude, $\mathscr{F} r$, and the grain roughness relative to flow depth (i.e. the inverse of the relative submergence),

$$
\mathrm{d} \equiv \frac{d}{h}
$$

and the Shields parameter, Sh. Subsequently, we plotted in Fig. 13 the non-dimensional parameters $\{\mathrm{d}, \mathscr{F} r, S h\}$ as a function of time. Also, supplementary videos 3 and 5 show an animation of the instantaneous values of the Froude and Shields numbers in the simulated area.

The exact values of discharge that caused the gravels to be entrained, and very large bedforms to build, are not known due to the impossibility of undertaking direct measurements and observations. However, using dimensional analysis, one can establish the physical similarity between sedimentological processes with different spatial scales and grain sizes. For consistency with our previous work (Bohorquez et al., 2016), values of the Shields parameter are set to $S h=0.03$ (blue line in Fig. 13b) for the typical threshold for gravel bedload transport (Julien, 2010). Bohorquez et al. (2019) revisited the criterion for the existence of dunes and antidunes using more than 500 flume experiments, measurements in gravel-bed streams and sandy large-rivers. Useful results related to the Altai gravel dunes (in terms of nondimensional numbers) are as follows. We found that very large dunes form in sandy deep rivers with $10^{-5} \leq \mathrm{d} \leq 10^{-4}, \mathscr{F} r \leq 0.2$ and $0.07 \leq S h \leq 2$. Shallower sandy rivers with the relative roughness of $10^{-4} \leq \mathrm{d} \leq 10^{-3}$ exhibit dunes at a higher Froude number $(0.2 \leq \mathscr{F} r \leq 0.4)$ and a narrower range of the Shields parameter $(0.07 \leq S h \leq 0.3)$. Lastly, 
a wide collection of dune experiments exist at the laboratory scale $\left(10^{-3} \leq \mathrm{d} \leq 10^{-2}\right)$ with $0.2 \leq \mathscr{F} r \leq 0.7$ and $0.03 \leq S h \leq 0.7$. Existing bedform data for gravels or coarse grains only involve antidunes in small streams with $\mathrm{d}>10^{-2}$ which is unrelated with the Altai bedforms, as explained below.

Fig. 13 shows active sediment transport (i.e. $S h>0.03)$ when the relative roughness lies in the interval $6 \times 10^{-5} \leq \mathrm{d} \leq 3 \times 10^{-4}$ with $\mathscr{F} r \leq 0.12$ in most of the locations of interest (except Baratal). The maximum Shields numbers satisfy the criterion $S h>0.11$ (orange line in Fig. 13b) for the formation of large gravel dunes (Carling, 1996a, 1999). Interestingly, the maximum local values of the simulated Shields parameter are similar to those measured in sandy rivers. Hence, the principles of physical similarity support the formation of giant gravel dunes in the Altai megaflood (Bohorquez et al., 2019).

Because of the proximity to the ice-dam, the velocity at Baratal was higher than in the rest of locations (see Fig. 12b) and, consequently, large values of the Shields parameter pertain (up to 0.68) with Froude numbers up to 0.3 (Figs. 13b and c, respectively). The flow was directed steadily due west towards the dam during the first 16.4 hours when sediment transport was active (Fig. 14b). During later times (16.7 $\leq t \leq 18.2 \mathrm{~h}$ ), the flow changed its direction and water locally drained down the valley-side swales towards the Chuja River. The dunes orientation represent development during most of the draining as the water level, and the velocity dropped abruptly at a late time.

The dynamics of flow over the Aktru bedforms differ compared with the previous locations because of the distance from the ice-dam and the fact that these bedforms are located in the small Esktykell sub-basin, sandwiched between the southern shoreline of the Kuray basin and a rocky rise within the Kuray basin: the Esktykell ridge. The flow accelerated progressively and achieved the threshold for erosion during the period $8 \leq t \leq 21 \mathrm{~h}$. The velocity varied between 4 and $6.1 \mathrm{~m} \cdot \mathrm{s}^{-1}$ at this time, attaining the maximum value at $t=10 \mathrm{~h}$. Later the velocity decreased, and the flow stopped at $t=24 \mathrm{~h}$. The Shields parameter followed the same trend as the velocity and was larger than the thresholds for sediment motions of 0.03 and 0.11 during the time intervals of $8.4<t<21.4$ and $9.1<t<17.8 \mathrm{~h}$, respectively. The Froude number was very low $(\mathscr{F} r<0.12)$. The initial deep flow was towards the northwest at $t<7.1 \mathrm{~h}$ (Fig. 14a), at which time shear stresses were low (Fig. 13b), but soon adopted a 
southeasterly direction $(7.1<t<22 \mathrm{~h})$, which is in accord with the direction of the Aktru bedforms, and at this time the bed shear stress was larger than 0.03. The reason for this later flow pattern is that, as the water level fell, the flow was trapped behind the Esktykell ridge, which prevented flow to the northwest, and the ridge funnelled flow to the southeast. However, latterly the flow changed to the north due to local bathymetric control allowing flow towards a col in the ridge. In the very late stages of drainage $(t>22 \mathrm{~h})$, the water level fell below the col and flow direction varied with time. The subcritical flow at Aktru is in accordance with the prior identification of these landforms as dunes (Carling, 1996a).

Within the Kuray bedform field box (Fig. 1a), there were no marked differences due to a generally similar broad flat bathymetry across the bedform field. However, as for Aktru, the field is located between the basin margin and the Esktykell ridge; the broad plain here is less constrained than at Aktru. The area was covered by water during most part of the drainage $(0<t<53 \mathrm{~h})$ (recall Fig. 12a). As for the Aktru dunes, the flow accelerated progressively above the location when the ice-dam breached. The velocity reached a maximum $\left(4.97 \mathrm{~m} \cdot \mathrm{s}^{-1}\right)$ at $t=5.9 \mathrm{~h}$ and later decreased to $1.6 \mathrm{~m} \cdot \mathrm{s}^{-1}$ at $t=7.2 \mathrm{~h}$ and increased again up to $4.5 \mathrm{~m} \cdot \mathrm{s}^{-1}$ at $t=17.4 \mathrm{~h}$, oscillating around $2 \mathrm{~m} \cdot \mathrm{s}^{-1}$ in the period $5<t<22.3 \mathrm{~h}$. A third peak of $4 \mathrm{~m} \cdot \mathrm{s}^{-1}$ developed at $t=21.5 \mathrm{~h}$. During the final stages of drainage $(t>22.3 \mathrm{~h})$ the Shields parameter was below 0.03. The flow direction was initially west for the first three hours during which time the water depth exceeded that of the confining Esktykell ridge to the north of the field. The flow swung to the east between 3 and $26 \mathrm{~h}$, at which time the bed shear stress was high between $5<t<22.3 \mathrm{~h}$. The bedforms are orientated to the east, suggesting that they formed slowly at this period of time due to the action of a mega-eddy (Fig. 9). If the bedload was moving for $S h>0.03$, then there was around 17 hours to build bedforms migrating eastwards, whereas if 0.11 is adopted, the period is only about 30 minutes. Large dunes in sandy rivers have been reported with $S h>0.06$ for similar values of the Froude number and relative roughness (Bohorquez et al., 2019), which implies three formation stages at $5.2<t<6.8,16.9<t<18$ and $20.8<t<22.2 \mathrm{~h}$ for a total duration of 4 hours. Note that, during the potential period of dune formation, the flow did not significantly changed its direction as shown in Fig. 9. Owing to the large flow depth and low velocities, the Froude number was very low (Fig. 13c). As for Aktru, having subcritical flow 
at Kuray is in accordance with the prior identification of these bedforms as dunes (Carling et al., 2016). Carling et al. (2016) related between three and five reactivation surfaces within the Kuray dunes to either intermittency in sediment transport during a single event or due to several distinct flood events reactivating the dunes. Due to the short period of potential transport modelled by Bohorquez et al. (2016, 1.3 hours), Carling et al. (2016) concluded that several floods were probably responsible for the reactivation surfaces. However, the present simulations indicate competent transport occurred for several hours with three pulses within the flow such that the reactivation surfaces could be related to one draining event. Such an interpretation would accord with the event being the final draining of the Kuray Basin as no lacustrine deposits occur within the troughs of the dunes that would signal refilling of the basin and submergence of the dunes at any time.

Close to the village of Chagun-Uzun in the Chuja basin, and close to the exit from the basin, are several large-scale flow-transverse undulations in the lee of some large hills, which have been described tentatively as erosional antidunes (Carling et al., 2002, 2009a; Herget, 2005). The water depth near Chagun-Uzun was maximum $(370 \mathrm{~m})$ at the initial outbreak, monotonously decreased during the flood, and became dry at $t=70 \mathrm{~h}$ (Fig. 12a). Water levels began to accelerate monotonously up to $t=10.9 \mathrm{~h}$ when the velocity (Fig. 12b) and the Shields parameter (Fig. 13b) achieved the maximums $5.8 \mathrm{~m} \cdot \mathrm{s}^{-1}$ and 0.22 , respectively. Froude numbers were small (Fig. 13c). Then, velocity decreased during the period $11<t<$ $25.6 \mathrm{~h}$, evacuating $88 \%$ of the initial Chuja basin volume. The wetted area of Chuja basin significantly reduced during this stage (Fig. 4). The Shields parameter was higher than the critical values at $3.9<t<21 \mathrm{~h}$ and so sediment could be eroded and transported through the valley towards Kuray. In a second phase, during the time interval of $25.6<t<60 \mathrm{~h}$, the velocity increased and decreased again below $1.6 \mathrm{~m} \cdot \mathrm{s}^{-1}$ but the Shields number remained below the threshold for erosion. As in our previous reconstruction (Bohorquez et al., 2016), the simulated Froude number remained low without satisfying the required constraint $\mathscr{F} r>$ 0.7 for the formation of antidunes (Carling and Shvidchenko, 2002; Bohorquez et al., 2019).

To conclude, the flow behaviour is reported for drainage over the bedforms at Kam Sugi, the rectangular box within the Chuja basin (Fig. 1a). This large area of bedforms lies on a complex ground that rises to the north. The bedforms are located predominately to the 

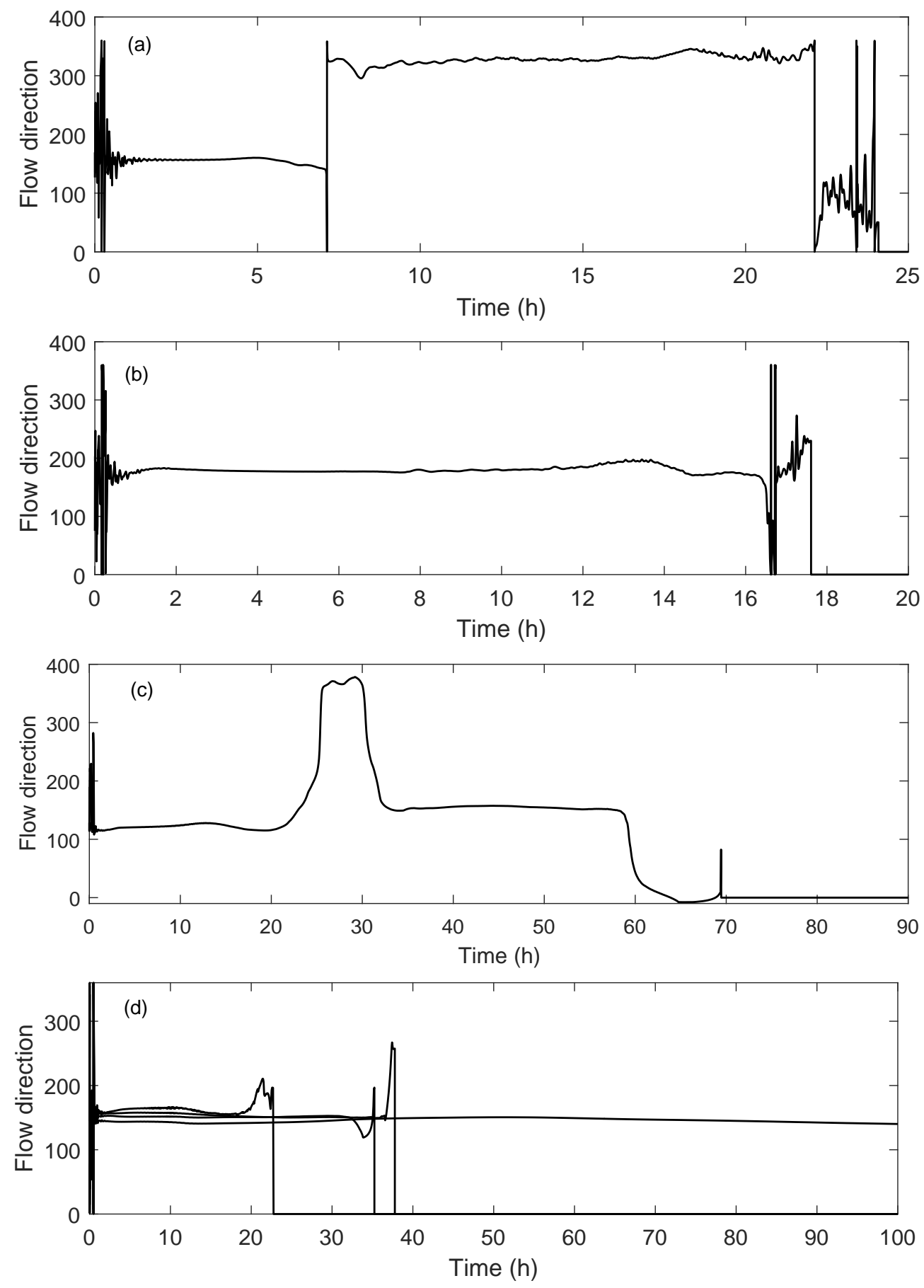

Fig. 14: Flow direction in (a) Aktru, (b) Baratal, (c) Chagan-Uzun and (d) Kam-Sugi. Notice that the values of 0, 90, 180, and 270 degrees correspond to the East, North, West, and South, respectively.

north of the M-52 road but also occur less evidently to the south of the road. Given the large area, the results from four hydraulic variables are reported, one located in each of the four corners of the rectangle. The water depth in the region of Kam Sugi depended on the exact 

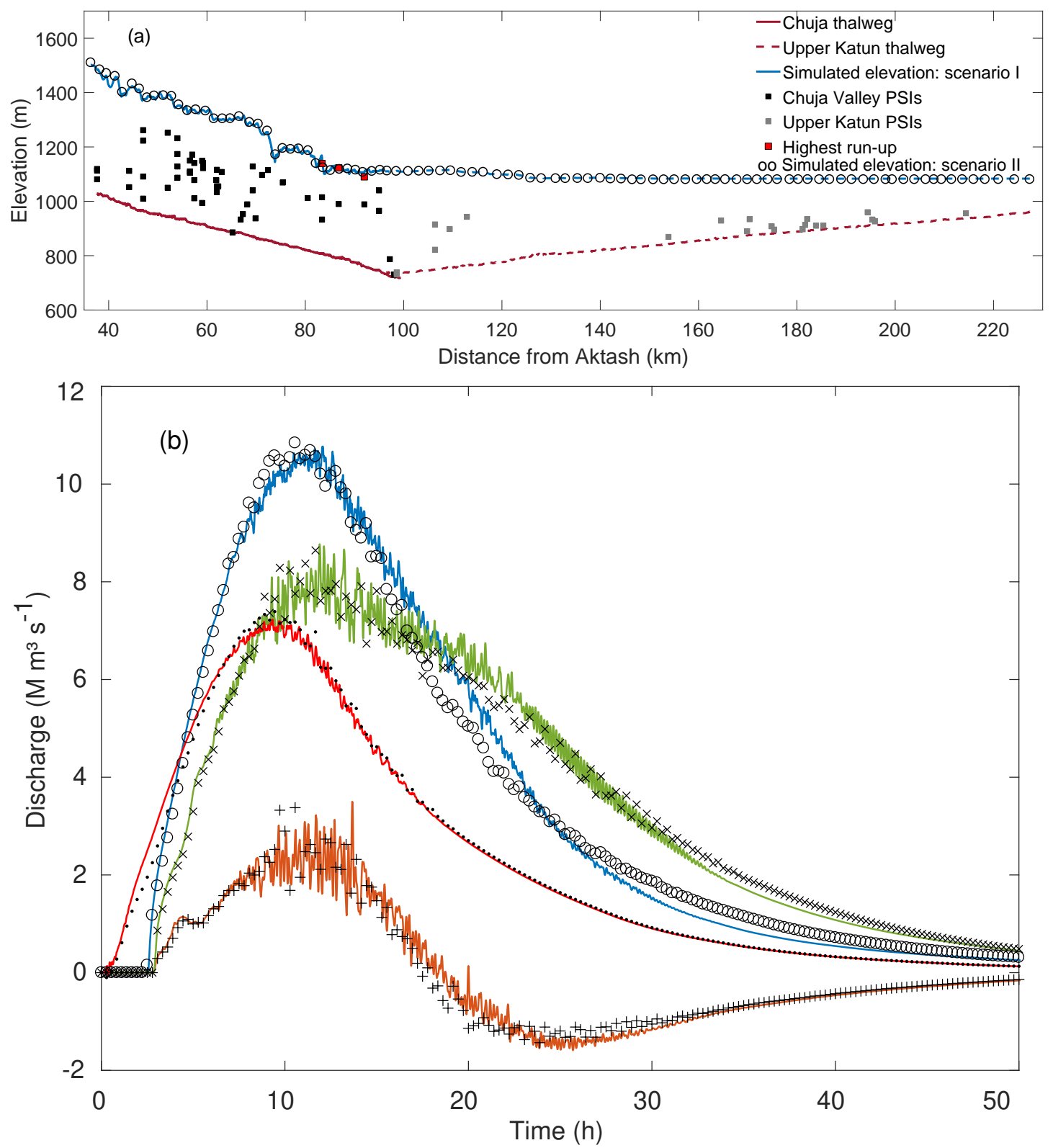

Fig. 15: Comparison between the optimal solutions in the full breach scenario I (continuous line) and the partial breach scenario II (symbols) with $E_{I}=28$ and $E_{I I}=42 \mathrm{~m} \cdot \mathrm{h}^{-1}$, respectively: (a) maximum elevation as Fig. 7a, (b) streamflows over the drainage network as Fig. 6a.

location of the probe and was maximum at the initial instant of time (Fig. 12a). The depth was nearly the same on the northwest and southeastern corners, where the local topography falls and consequently in the inset of Fig. 12a there are two overlapping curves. Most of the region was completely dry at $t>40 \mathrm{~h}$ although a very small subregion remained covered by 

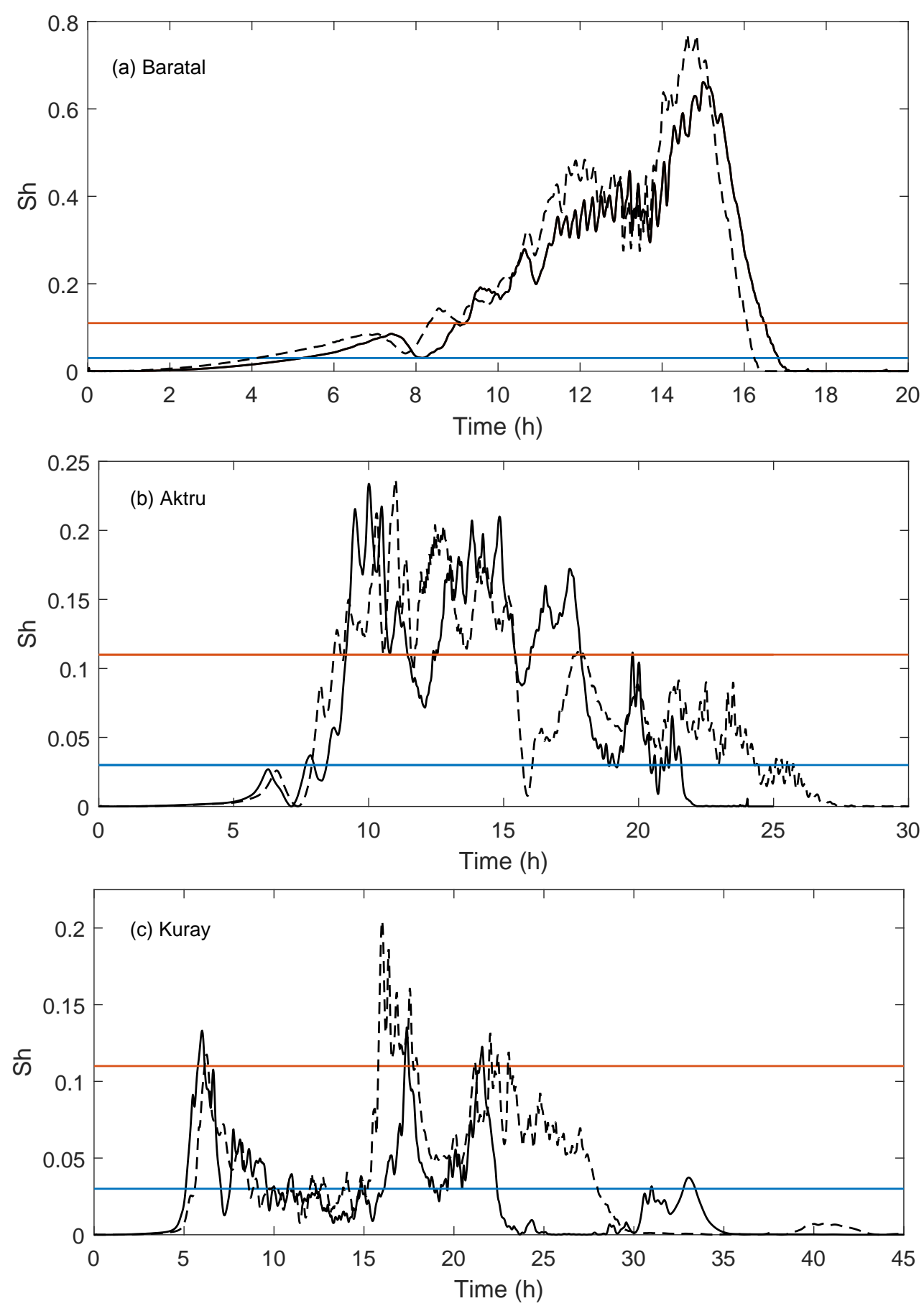

Fig. 16: Comparison between the Shields number in Kuray dune fields in the full breach scenario I (continuous line) and the partial breach scenario II (dashed line) with $E_{I}=28$ and $E_{I I}=42 \mathrm{~m} \cdot \mathrm{h}^{-1}$, respectively.

water at the end of the simulation. When the Shields parameter was larger than the erosion threshold, the flow direction was westwards. This fact was so because Kam Sugi lies on the main path where water was routed towards Kuray. In the southern part of the field, the 

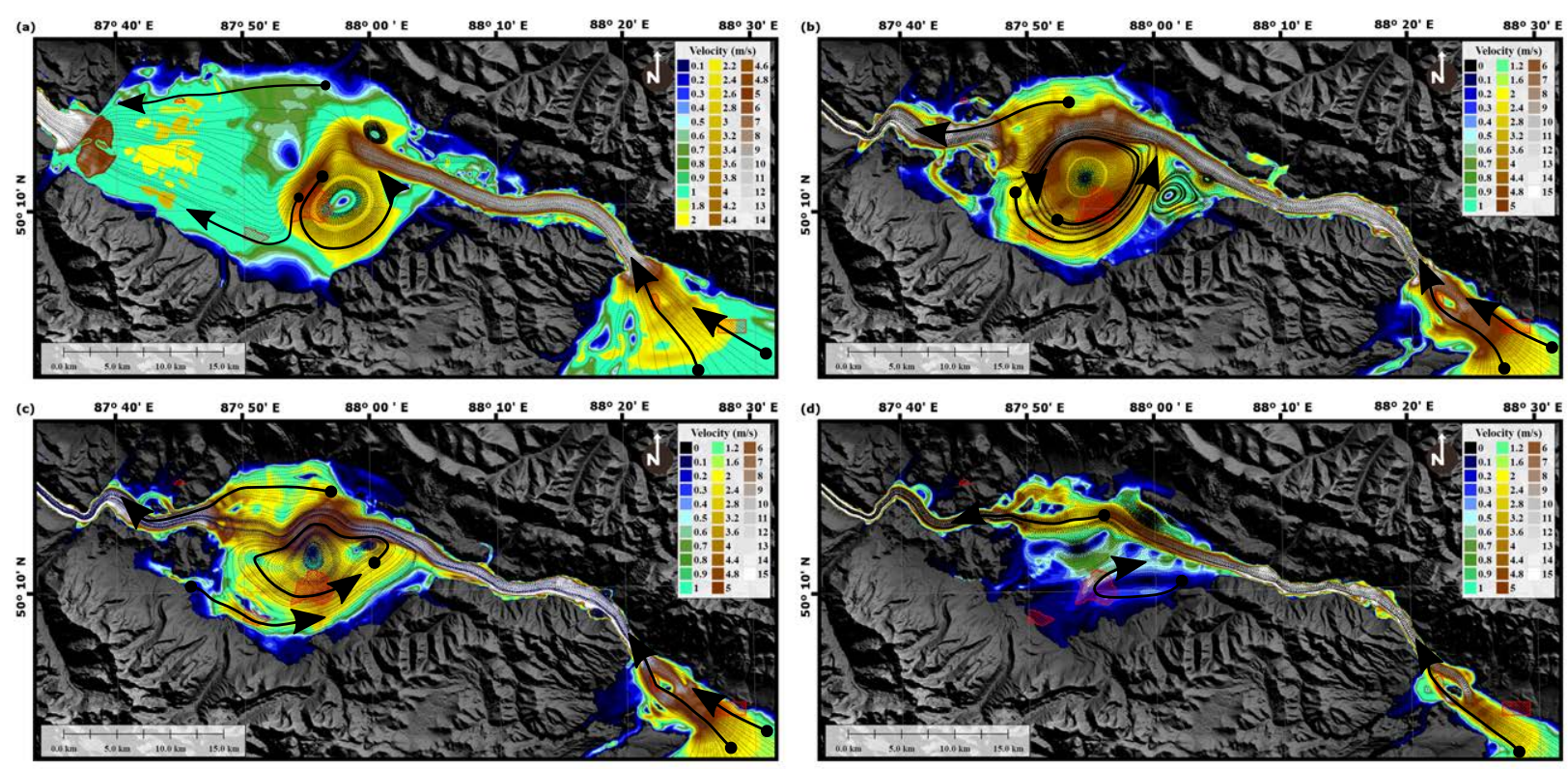

Fig. 17: As Fig. 9 with a partial breach of the ice dam.

Shields parameter was larger than the critical value of 0.03 for more than $48 \mathrm{~h}$. The flow direction changed when the depth was lower than $40 \mathrm{~m}$ at each probe, but this fact should not modify the orientation of the dune field because the Shields parameter was too low at that time.

\subsection{Similarities and differences between a full and partial breach}

In this section, we consider the possibility that the ice dam was stronger at the northern side along the former Chuja valley via Aktash than the southern side supported by Mashej Glacier (Herget, 2005). Once the lake reached the surface of the ice dam, thermal erosion of the ice caused rapidly widening and deepening of the sub-aerial channel in the supraglacial ice, as has been previously assumed by Baker et al. (1993).

The ice incision rate was retrodicted following the same procedure as for the full breach scenario. We ran multiple simulations by varying the value of the incision rate, $E$, and best fitted the elevation of the highest run-up sediments in the Chuja valley. As advanced in Section 2.2, the ensuing value of the incision rate $\left(E_{I I}=42 \mathrm{~m} \cdot \mathrm{h}^{-1}\right)$ is larger than before $\left(E_{I}=28 \mathrm{~m} \cdot \mathrm{h}^{-1}\right)$ because a faster erosion of the ice-dam is required to erode the same area as in the complete breach. Fig. 15a compares the maximum water altitudes simulated in scenarios I (blue line) and II (circles). Both solutions overlap. Also, hydrographs for 
major sections across the flood route are compared in Fig. 15b, in which continuous lines and discrete symbols depict the full and partial breach solutions, respectively. Again, the agreement between both results is excellent. A slight difference appears in the Chuja valley during the falling limb, but this fact does not affect the maximum elevations that developed at the peak discharge. In the valley pathway from Chuja to Kuray the hydrograph is the same in both scenarios. Taking into account these results, it is evident that the dynamics of the megaflood downstream of the ice-dam and within the Chuja lake are the same independently of the configuration of the failure. We confirmed this statement by comparing the local probes in the Chuja lake basin and along the drainage network downstream of the dam. For the sake of the brevity, below we only comment on the differences that we found in the Kuray lake basin.

Some quantitative, but not qualitative, differences occur in the dune fields of Baratal, Aktru and Kuray, as shown in Fig. 16, due to the direction of the streamlines that are slightly displaced southernly (Fig. 17). Notice that masses of water from the Chuja megajet were redirected and discharged through the breached dam, and described an envelope of the vortex in the southern expansion area. Hence, in the partial breach, the flow was routed along the southern valley while in the full breach the flow bifurcated in the dammed area (Fig. 9). When comparing the nondimensional shear stresses in Baratal (Fig. 16a), we found that the peak value increased up to $S h=0.76$ (dashed line), but this does not make a notable difference with respect the maximum value $S h=0.66$ of the full breach configuration (solid line). The direction of the flow in Baratal did not change during the erosional stage $(S h>0.03)$. In Aktru, see Fig. 16b, sediment transport lasted 4 hours longer in the partial breach than in the full breach. In both configurations, the Shields value remained above the threshold of erosion in the period $8<t<21.5 \mathrm{~h}$. A slight difference of the second configuration with respect to the first one is that such a condition was maintained up to $t=25.5 \mathrm{~h}$, while the Shields was lower than 0.03 for $t>21.5 \mathrm{~h}$ in the full breach. The maximum Shields number in the partial breach $(S h=0.233)$ was nearly the same as for the first failure configuration $(S h=0.236)$ described in Section 3.3. Again, the direction of the flow did not change regarding the previous result. There were no marked up differences between the results of the full and partial breach scenarios. Finally, we arrived at the similar 
conclusions when analysing the flow in the Kuray dune field (Fig. 16c), where sediment transport occurred for 22.4 hours (Scenario II) instead of 17.2 hours (Scenario I).

\section{Discussions and comparisons with previous works}

We discuss two points that have attracted interest since the earliest studies of the Altai megaflood, namely: the peak discharge developing giant bars in the Chuja Valley; and, both the stage of the flood and the hydraulic conditions when the most extensive dunefield of Kuray was formed.

Originally, within the area occupied by the ice dam south of Aktash (Fig. 2), Baker et al. (1993) found a peak streamflow of $18.5 \mathrm{M} \mathrm{m}^{3} \cdot \mathrm{s}^{-1}$ using the one-dimensional steadystate flow model implemented in HEC-RAS. Further downstream, Herget (2005) inferred the peak discharge by best fitting the run-up sediments (HWM-PSIs) and the simulated water elevations in the Chuja valley. His step-backwater calculations of flow routing downstream of the dam yielded a peak discharge of 8 to $10 \mathrm{M} \mathrm{m}^{3} \cdot \mathrm{s}^{-1}$, with a peak time of $16.8 \mathrm{~h}$. These values may be compared with those reported by Carling et al. (2010) in the same valley, i.e. $9-11 \mathrm{M} \mathrm{m}^{3} \cdot \mathrm{s}^{-1}$ using the two-dimensional unsteady Saint-Venant equations as in the current work.

Major novelties of the current whole-system approach are the evaluation of the peak discharge (i.e. $10.5 \mathrm{M} \mathrm{m}^{3} \cdot \mathrm{s}^{-1}$ ) and the time when it occurred (i.e. $11 \mathrm{~h}$ ) as an output (rather than input) of the model, recall the hydrographs in Fig. 6. Our peak streamflow is in close agreement with Herget (2005) and Carling et al. (2010) by considering a finite time for down-cutting through the ice between $E=28$ (full breach) and $42 \mathrm{~m} \cdot \mathrm{h}^{-1}$ (partial breach). However, previous paleohydraulic reconstructions truncated the domain nearby the Upper Katun valley and, consequently, could not capture the backwater effects at the confluence between the Chuja and Katun rivers completely. In this work, the reconstructed flood inundated the highest run-up records which lie above a bar surface that Herget (2005) interpreted as being eroded by a standing wave, which is consistent with our paleohydraulic reconstruction. Also, we found the achievement of a quasi-steady uniform state in the Chuja valley, which corroborates the assumption of uniform flow in step-backwater reconstructions (Baker et al., 1993; Herget, 2005). 

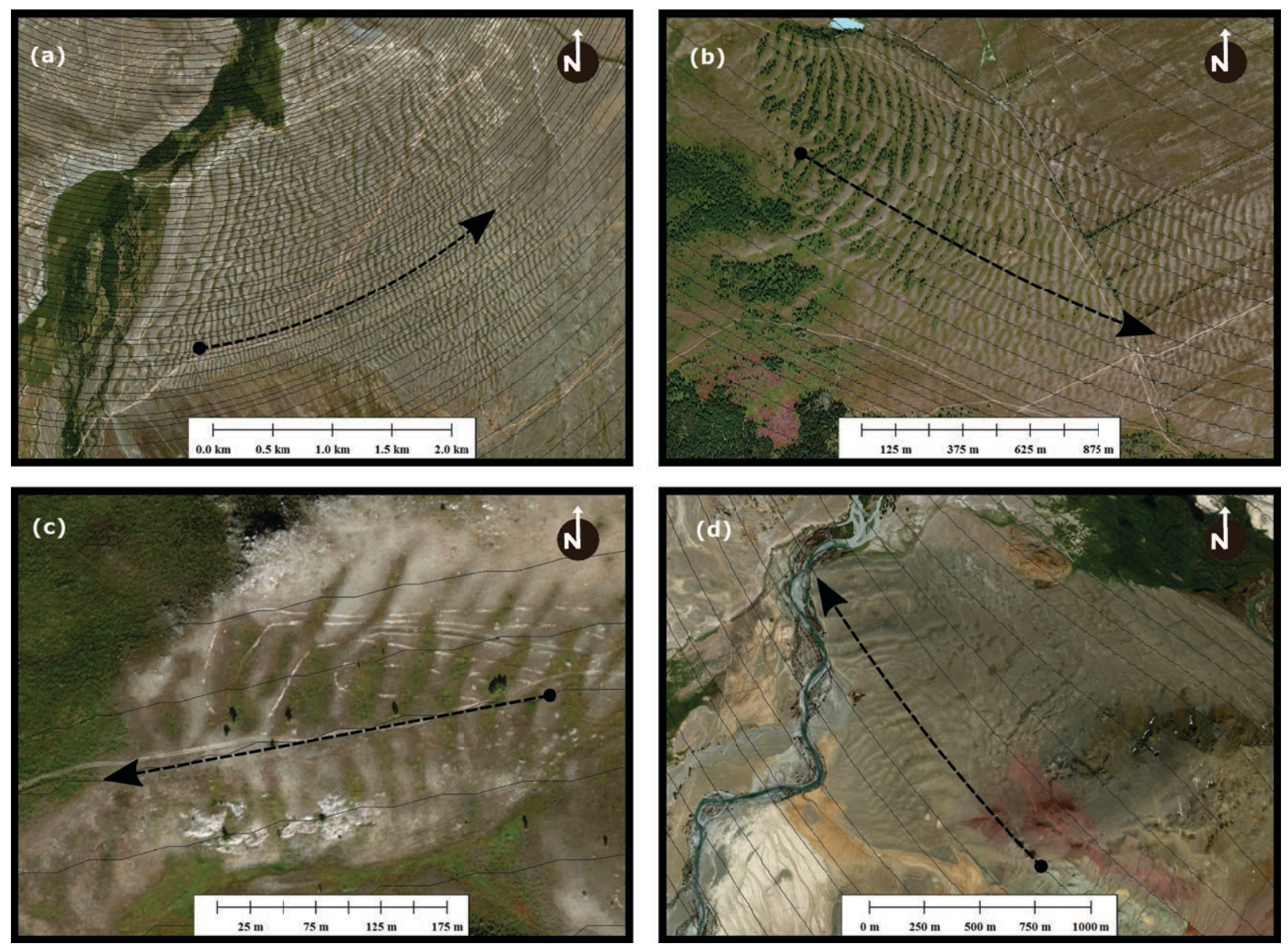

Fig. 18: Detail view of the streamlines (thin solid lines) above the dune fields of (a) Kuray, (b) Aktru, (c) Baratal and (d) Chagan-Uzun when the Shields number was near its maximum value at each location (i.e. $t=17.5,10,12$ and $11 \mathrm{~h}$, respectively). The arrow indicates the flow direction.

Furthermore, our numerical results allow the study of the formation of fields of gravel dunes in Kuray and Chuja basins as we coupled these regions in the computational domain with the eroded ice-dam and the downstream drainage network (recall Fig. 4). Below we discuss the four of the dune fields considered in Section 3.3 (see Fig. 18): Kuray, Aktru, Baratal and Chagan-Uzun.

Giant dunes in Kuray represent the most notable example of subaqueous gravel dune fields on Earth (Carling, 1999), see Fig. 18a. There, the wavelength varies in the range of $60-200 \mathrm{~m}$, the characteristic dune height is about $10-16 \mathrm{~m}$, and the mean grain size is $35 \mathrm{~mm}$ (Carling, 1996a). Preliminary results by Carling (1996b) reported the onset and stabilisation of such dunes when the discharge across the breadth of the dunefield was of the order of 
$5 \times 10^{4}$ and $2 \times 10^{4} \mathrm{~m}^{3} \cdot \mathrm{s}^{-1}$, respectively, and the flow speed was between 1.5 and $8 \mathrm{~m} \cdot \mathrm{s}^{-1}$. Later on, Inishev et al. (2015) simulated the two-dimensional flow numerically and found a minimum flow depth and speed of $400 \mathrm{~m}$ and $4-5 \mathrm{~m} \cdot \mathrm{s}^{-1}$, assuming a steady state and the same inflow and outflow discharges in the Kuray lake. Conversely, in the current work we have shown that the flow regime in the Kuray Basin was two-dimensional and unsteady in the period $5 \leq t \leq 22 \mathrm{~h}$ (see the hydrographs in Fig. 6a), when the high velocities sustained the formation of the Kuray dune field for 17 hours (Fig. 12b). Three peak velocities of 4.9, 4.5 and $3.9 \mathrm{~m} \cdot \mathrm{s}^{-1}$ occurred at 5.96, 17.37 and $21.57 \mathrm{~h}$, when the flow depth was 526, 273 and $192 \mathrm{~m}$, and the inflow (outflow) discharge achieved $7.7(5.9), 7(3.5)$ and $4.4(2.3) \mathrm{M} \mathrm{m}^{3} \cdot \mathrm{s}^{-1}$ (see filled circles in Fig. 19a). The relative difference between the discharges from the Chuja lake to the Kuray lake and from the Kuray lake to the Chuja valley was, respectively, 31, 102 and $92 \%$ (Fig. 19b). This result also makes a significant difference with respect to the instantaneous dam-break simulation that predicts the formation of the dunes in less than $1.5 \mathrm{~h}$ (Bohorquez et al., 2016). The finite time for breaching through the ice dam is key in the developments of megaflood scale bedforms. Furthermore, our new simulation captures with accuracy the direction of the dunes nearly perpendicular to the streamlines in Fig. 18a. Hence, to reproduce the dynamics of the flow that built the giant dunes, the current whole system model of megaflood is required.

Aktru bedforms are located in the small Esktykell sub-basin (Fig. 18b), sandwiched between the southern shoreline of the Kuray basin and a rocky rise within the Kuray basin (i.e. Esktykell ridge). There, the velocity exhibited three local maxima of $6,5.3$ and $4.5 \mathrm{~m} \cdot \mathrm{s}^{-1}$ (Fig. 12b) with Shields numbers higher than 0.2 at 10, 14.8 and 17 hours (Fig. 13b). The first peak nearly occurred when the inflow and outflow discharges were a maximum (see diamonds in Fig. 19a). Later, the flow decelerated but the Shields parameter remained around 0.2 for 9 hours. Figure 18b depicts a good agreement between the simulated flow direction and the dune crests, which was sustained during the whole period of formation of the dune field (Fig. 14a). The relative difference between the discharges at the inlet and outlet of the Kuray lake increased from $50 \%$ to $100 \%$ in the stage of dune formation (Fig. 19b), invalidating Inishev et al.'s (2015) modelling simplifications.

Near the ice-dam, the Baratal dune field exhibits smaller dimensions (2 m height and 

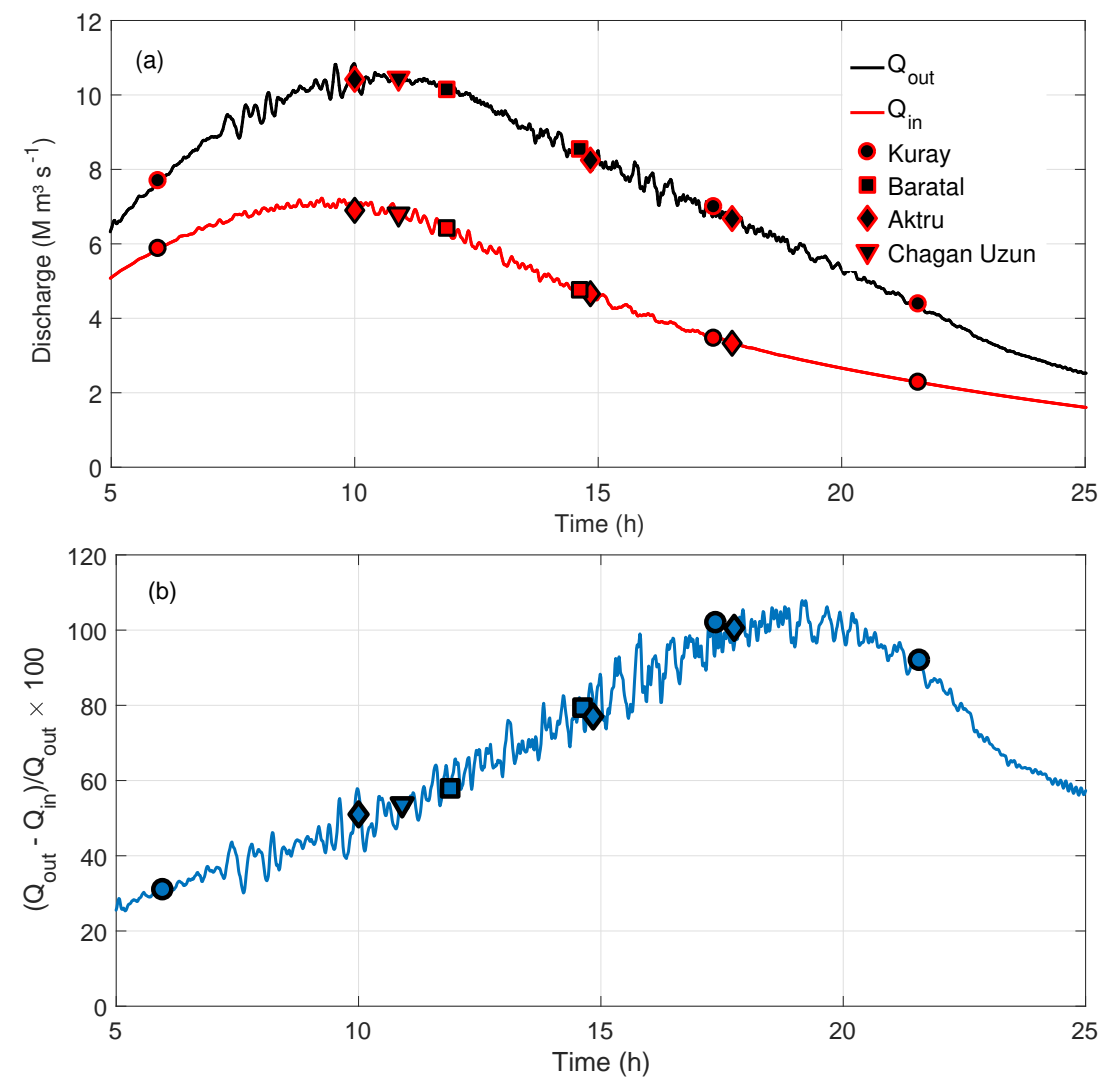

Fig. 19: (a) Hydrographs and instants of time when the bed shear stress and the velocity were local maxima in the dune fields of Kuray (circle), Baratal (square), Aktru (diamond) and Chagan Uzun (inverted triangle). $Q_{i n}$ is the discharge from the Chuja lake to the Kuray lake. $Q_{o u t}$ represents the discharge from the Kuray lake to the Chuja valley. (b) Relative difference between the inflow and outflow in the Kuray lake.

$46 \mathrm{~m}$ wavelength), see Fig. 18c. The simulated flow direction was aligned towards the outlet of the Kuray lake during their formation, following the orientation of the bedforms. This result agrees with the observation by Herget (p. 79, 2005) who stated "The dune field of Baratal ... consists of two-dimensional dunes, which are oriented in a western direction, while the valley itself is oriented in a south-western direction. The dunes are deposited on the slope of the valley and were formed by a current during the drainage of the ice-dammed lake, which was different from the orientation of the valley". The highest bed shear stresses in Baratal was achieved during the falling limb (see filled squares in Fig. 19a), highlighting the relevance of simulating the drainage of the Kuray-Chuja lakes subject to the correct transient hydrograph at the dam. 
Another example of bedforms occurs in the Chuja basin (Fig. 18d). The bedform height and wavelength in Chagan-Uzun are $23 \mathrm{~m}$ and $320 \mathrm{~m}$ (Herget, 2005). These bedforms were interpreted to be erosional antidunes by Herget (2005) and Carling and Shvidchenko (2002), although the simulations of Bohorquez et al. (2016) could not reproduce supercritical flow at this location. On this occasion, the most erosive flow occurred with the peak discharge (inverted triangle in Fig. 19a) and a Froude number ( $\mathscr{F} r=0.11$, Fig. 13c) below the threshold for antidunes (Bohorquez et al., 2019). The agreement between the direction of the simulated flow and bedforms is excellent (Fig. 18d). Further upstream, we reported Shields number below the threshold for sediment motion (Fig. 11a) which preclude the formation of dunes and antidunes in the rest of the Chuja Basin, in agreement with the absence of bedforms reported by Carling (1996a), Carling et al. (2002) and Herget (2005).

The good accordances between the retrodicted hydraulic conditions over fields of bedforms, the required values to form them and the flow directions serve to validate the ice breach model (4)-(5) indirectly. Regarding the hypothesis of over-topping and incision of the impounding ice mass (see Fig. 2), the following results support our assumptions. First, the high elevations of the water surface $(<2100 \mathrm{~m})$, the flood extents and the large Shields numbers simulated in such an area imply that glacier moraines in the Chuja valley downstream of the ice-dam were washed out by the outburst flood (Herget, 2005). The terminal moraine deposits below $1420 \mathrm{~m}$ in the Chuja Gorge, near Chibit and Aktash (Fig. 2), indeed correspond with a younger glacier advance (Rudoy, 2002; Reuther et al., 2006; Blomdin et al., 2016). Different failure mechanisms as drainage through subglacial tunnels are ruled out (Carling et al., 2010). In such a case, the water level would be lower than $1530 \mathrm{~m}$ (i.e. the maximum simulated elevation below the dam, recall Fig. 5) and moraine deposits would be preserved at $1530-2100 \mathrm{~m}$, which contradicts their present absence. Lastly, an instantaneous ice-dam break is unrealistic because the water level in the Chuja Valley would be much higher than the run-up sediments (Fig. 3).

\section{Conclusions}

Numerical simulation of lake drainage and flood routing can produce estimates of the breach time and the incision speed during megafloods in the Late Pleistocene. The current 
study considers the Altai megaflood that occurred during the drainage of the Kuray-Chuja lake. The incorporation of a simple over-topping breach model yields a peak discharge that reconciled with previous ice-dam failure modelling as the inferred peak streamflow from the lake $\left(10.5 \mathrm{M} \mathrm{m}^{3} \cdot \mathrm{s}^{-1}\right)$ lies in the interval $9-11 \mathrm{M} \mathrm{m}^{3} \cdot \mathrm{s}^{-1}$ predicted from prior models of the flow down the valley below the impoundment (Carling et al., 2010). By considering different failure scenarios to ascertain whether the breach geometry can be inferred from numerical modelling, the ice incision rate and the timing of the drainage event could be determined. The mean incision rate was constrained in the narrow range $28 \leq E \leq 42 \mathrm{~m} \cdot \mathrm{h}^{-1}$ and the characteristic time for the complete incision of the ice-dam was about 24-36 hours. The maximum streamflow occurred at 10.5-11 hours during the breach of the ice-dam. The lakes had drained $45 \%$ of the stored water volume at that time and the $95 \%$ in 33.8 hours.

Furthermore, the whole-system model of the basin-scale drainage behaviour during the Altai megaflood gives also details at specific points within the lake to determine the local hydrodynamic response and formation of megaflood scale bedforms. In most of the Chuja basin, the velocities and the shear stresses were too low to sculpt giant dunes. Exceptional giant erosional bedforms developed due to the throttling effect of the constriction between the Chuja and Kuray basins in constraining the evacuation of water from the Chuja basin. The time intervals of growth and development of bedforms in Chagan-Uzun $(4<t<21 \mathrm{~h})$ and Kam-Sugi $(6.5<t<30)$ indicate that the bedforms mostly evolved during the intermediate stage of drainage, when the volume of Chuja lake decreased from $91 \%$ to $7 \%$. Similarly, the largest dune fields in the Kuray basin developed in the period $5<t<30 \mathrm{~h}$ as the drained volume increased from $13 \%$ to $93 \%$. At that time, bed shear stresses were adequate to mobilise sediment to build bedforms, such as fluvial dunes, and the directions of the modelled flows are in accord with the orientation of the various tracts of bedforms. In comparison with the instantaneous dam-break scenario, we found that considering a finite time for down-cutting through the ice-dam is essential to obtain physically plausible results.

A future challenge will be to relate the incision rate $(E)$ to the physics of ice-melt beneath the flood water running over the dam crest. Melting ice involves transferring heat energy to the ice from the running water at a pressure of one atmosphere. However, as well as considering ice and water temperature, the actual melt rate is a function of the thermal 
conductivity of the (sediment-laden?) ice, the hydraulic gradient and the breach area. These latter three parameters are controlling variables during incision and uncertainty analyses will be required to relate $E$ to the physics of melting ice.

We conclude by pointing out the potential value in using tracts of relict bedforms to constrain the behaviour of the ice-dam failure within other basins worldwide. The wholesystem model serves to match the dynamic simulated floodwater levels and geomorphological evidence downstream of the ice-dam, such as bar heights and run-up sediments, using systematic flood-flow modelling, as well as to correlate the simulated hydraulic variables with the required values to form bedforms.

\section{Acknowledgements}

P.B. would like to express his sincere appreciation to Prof. Jürgen Herget for fruitful discussions that motivated the re-simulation of the Altai megaflood. This work was sup-

ported by the Spanish Ministry of Science, Innovation and Universities (MICINN/FEDER, UE) under Grant SEDRETO CGL2015-70736-R. P.R.J. was supported by the European Social Fund and the University of Jaén. J.D. del Moral-Erencia is thanked for the image reproduced here as Fig. 1.

\section{References}

Abril-Hernández, J. M., Periáñez, R., O’Connor, J. E., Garcia-Castellanos, D., 2018. Computational Fluid Dynamics simulations of the Late Pleistocene Lake Bonneville Flood. J. Hydrol. 561, 1-15, https://doi.org/10.1016/j.jhydrol.2018.03.065.

Alho, P., Baker, V. R., Smith, L., 2010. Paleohydraulic reconstruction of the largest Glacial Lake Missoula draining(s). Quat. Sci. Rev. 29 (23-24), 3067-3078, https://doi.org/10.1016/j.quascirev.2010.07.015.

Baker, V. R., 1987. Paleoflood hydrology and extraordinary flood events. J. Hydrol. 96, 79-99, https://doi.org/10.1016/0022-1694(87)90145-4. 
Baker, V. R., Benito, G., Rudoy, A. N., 1993. Paleohydrology of late pleistocene superflooding, Altay mountains, Siberia. Science 259, 348-350, https://doi.org/10.1126/science.259.5093.348.

Blomdin, R., Heyman, J., Stroeven, A. P., Hättestrand, C., Harbor, J. M., Gribenski, N., Jansson, K. N., Petrakov, D. A., Ivanov, M. N., Alexander, O., Rudoy, A. N., Walther, M., 2016. Glacial geomorphology of the Altai and Western Sayan Mountains, Central Asia. J. Maps 12 (1), 123-136, https://doi.org/10.1080/17445647.2014.992177.

Bohorquez, P., 2010. Competition between kinematic and dynamic waves in floods on steep slopes. J. Fluid Mech. 645, 375-409, https://doi.org/10.1017/S002211200999276X.

Bohorquez, P., 2016. Paleohydraulic reconstruction of modern large floods at subcritical speed in a confined valley: Proof of concept. Water (Switzerland) 8 (12), https://doi.org/10.3390/w8120567.

Bohorquez, P., Cañada Pereira, P., Jimenez-Ruiz, P. J., del Moral-Erencia, J. D., 2019. The fascination of a shallow-water model for the formation of megaflood-scale dunes and antidunes. Earth-Sci. Rev. 193, 91-108, https://doi.org/10.1016/j.earscirev.2019.03.021.

Bohorquez, P., Carling, P. A., Herget, J., 2016. Dynamic simulation of catastrophic late Pleistocene glacial-lake drainage, Altai Mountains, central Asia. Int. Geol. Rev. 58 (14), 1795-1817, https://doi.org/10.1080/00206814.2015.1046956.

Bohorquez, P., Darby, S. E., 2008. The use of one- and two-dimensional hydraulic modelling to reconstruct a glacial outburst flood in a steep Alpine valley. J. Hydrol. 361 (3-4), 240261, https://doi.org/10.1016/j.jhydrol.2008.07.043.

Carling, P. A., 1996a. Morphology, sedimentology and palaeohydraulic significance of large gravel dunes, Altai Mountains, Siberia. Sedimentology 43 (4), 647-664, https://doi.org/10.1111/j.1365-3091.1996.tb02184.x.

Carling, P. A., 1996b. A preliminary palaeohydraulic model applied to late Quaternary gravel dunes: Altai Mountains, Siberia. Geological Society, London, Special Publications 115 (1), 165-179, https://doi.org/10.1144/GSL.SP.1996.115.01.13. 
Carling, P. A., 1999. Subaqueous gravel dunes. J. Sediment. Res. 69 (3), 534, https://doi.org/10.2110/jsr.69.534.

Carling, P. A., 2013. Freshwater megaflood sedimentation: What can we learn about generic processes? Earth-Sci. Rev. 125, 87-113, https://doi.org/10.1016/j.earscirev.2013.06.002.

Carling, P. A., Bristow, C. S., Litvinov, A. S., 2016. Ground-penetrating radar stratigraphy and dynamics of megaflood gravel dunes. J. Geol. Soc. 173 (3), 550-559, https://doi.org/10.1144/jgs2015-119.

Carling, P. A., Herget, J., Lanz, J. K., Richardson, K., Pacifici, A., 2009a. Channelscale erosional bedforms in bedrock and in loose granular material: Character, processes and implications. In: Burr, D. M., Carling, P. A., Baker, V. R. (Eds.), Megaflooding on Earth and Mars. Cambridge University Press, Cambridge, pp. 13-32, https://doi.org/10.1017/CBO9780511635632.002.

Carling, P. A., Kirkbride, A. D., Parnachov, S., Borodavko, P. S., Berger, G. W., 2002. Late Quaternary catastrophic flooding in the Altai Mountains of south-central Siberia: A synoptic overview and an introduction to flood deposit sedimentology. In: Martini, I. P., Baker, V. R., Garzón, G. (Eds.), Flood and Megaflood Processes and Deposits. John Wiley \& Sons, Ltd, pp. 17-35, https://doi.org/10.1002/9781444304299.ch2.

Carling, P. A., Knaapen, M., Borodavko, P., Herget, J., Koptev, I., Huggenberger, P., Parnachev, S., 2011. Palaeoshorelines of glacial lake Kuray-Chuja, south-central Siberia: Form, sediments and process. In: Martini, I. P., French, H. M., Pérez-Alberti, A. (Eds.), Ice-marginal and periglacial processes and sediments. Vol. 354. Geological Society, London, Special Publications, pp. 111-128, https://doi.org/10.1144/SP354.7.

Carling, P. A., Martini, I. P., Herget, J., Borodavko, P., Parnachov, S., 2009b. Megaflood sedimentary valley fill: Altai Mountains, Siberia. In: Burr, D. M., Carling, P. A., Baker, V. R. (Eds.), Megaflooding on Earth and Mars. Cambridge University Press, Cambridge, pp. 243-264, https://doi.org/10.1017/CBO9780511635632.013. 
Carling, P. A., Shvidchenko, A. B., 2002. A consideration of the dune:antidune transition in fine gravel. Sedimentology 49 (6), 1269-1282, https://doi.org/10.1046/j.13653091.2002.00496.x.

Carling, P. A., Villanueva, I., Herget, J., Wright, N., Borodavko, P., Morvan, H., 2010. Unsteady 1D and 2D hydraulic models with ice dam break for Quaternary megaflood, Altai Mountains, southern Siberia. Global Planet. Change 70 (1-4), 24-34, https://doi.org/10.1016/j.gloplacha.2009.11.005.

Carrivick, J. L., 2006. Application of 2D hydrodynamic modelling to high-magnitude outburst floods: An example from Kverkfjöll, Iceland. J. Hydrol. 321 (1-4), 187-199, https://doi.org/10.1016/j.jhydrol.2005.07.042.

Denlinger, R. P., O'Connell, D. R. H., 2010. Simulations of cataclysmic outburst floods from Pleistocene glacial lake Missoula. Bull. Geol. Soc. Am. 122 (5-6), 678-689, https://doi.org/10.1130/B26454.1.

Feldman, A. D., 1981. HEC models for water resources system system simulation: theory and experience. Adv. Hydrosci. 12, 297-423, https://doi.org/10.1016/B978-0-12-0218127.50010-9.

Herget, J., 2005. Reconstruction of Pleistocene ice-dammed lake outburst floods in the Altai Mountains, Siberia. Special Paper of the Geological Society of America 386, 1-118, https://doi.org/10.1130/0-8137-2386-8.1.

Herget, J., Roggenkamp, T., Krell, M., 2014. Estimation of peak discharges of historical floods. Hydrol. Earth Syst. Sci. 18 (10), 4029-4037, https://doi.org/10.5194/hess-18-40292014.

Huang, W., Cao, Z.-X., Carling, P. A., Pender, G., 2014. Coupled 2D hydrodynamic and sediment transport modeling of megaflood due to glacier dam-break in Altai Mountains, Southern Siberia. J. Mt. Sci. 11 (6), 1442-1453, https://doi.org/10.1007/s11629-014-30322. 
Huang, W., Cao, Z. X., Pender, G., Liu, Q. Q., Carling, P. A., 2015. Coupled flood and sediment transport modelling with adaptive mesh refinement. Sci. China Technol. Sci. 58 (8), 1425-1438, https://doi.org/10.1007/s11431-015-5880-6.

Inishev, N. G., Rudoy, A. N., Zemtsov, V. A., Vershinin, D. A., 2015. The first computer model of currents in the Kurai intermountane basin, Altai, under release of a glacial-dammed lake. Doklady Earth Sciences 461 (1), 283-285, https://doi.org/10.1134/S1028334X15030125.

Julien, P. Y., 2010. Erosion and Sedimentation. Cambridge University Press, Cambridge, https://doi.org/10.1017/CBO9780511806049.

Lighthill, M. J., Whitham, G. B., 1955. On kinematic waves. Part I: Flood movement in long rivers. Part II: A theory of traffic flow on long crowded roads. Proc. R. Soc. A 229 (1178), 281-345, https://doi.org/10.1098/rspa.1955.0088.

Lumbroso, D., Gaume, E., 2012. Reducing the uncertainty in indirect estimates of extreme flash flood discharges. J. Hydrol. 414-415, 16-30, https://doi.org/10.1016/j.jhydrol.2011.08.048.

Monnier, J., Couderc, F., Dartus, D., Larnier, K., Madec, R., Vila, J.-P., 2016. Inverse algorithms for 2D shallow water equations in presence of wet dry fronts. Application to flood plain dynamics. Adv. Wat. Res. 97, 11-24, https://doi.org/10.1016/j.advwatres.2016.07.005.

Reuther, A. U., Herget, J., Ivy-Ochs, S., Borodavko, P., Kubik, P. W., Heine, K., 2006. Constraining the timing of the most recent catalysmic flood event from ice-dammed lakes in the Russian Altai Mountains, Siberia, using cosmogenic in situ 10be. Geology 34 (11), 913-916, https://doi.org/10.1130/G22755A.1.

Rudoy, A. N., 2002. Glacier-dammed lakes and geological work of glacial superfloods in the late Pleistocene, southern Siberia, Altai mountains. Quat. Int. 87 (1), 119-140, 10.1016/S1040-6182(01)00066-0. 
Rudoy, A. N., Baker, V. R., 1993. Sedimentary effects of cataclysmic late Pleistocene glacial outburst flooding, Altay Mountains, Siberia. Sediment. Geol. 85 (1-4), 53-62, https://doi.org/10.1016/0037-0738(93)90075-G.

Singh, V. P., 2002. Is hydrology kinematic? Hydrol. Process. 16 (3), 667-716, https://doi.org/10.1002/hyp.306.

Winsemann, J., Alho, P., Laamanen, L., Goseberg, N., Lang, J., Klostermann, J., 2016. Flow dynamics, sedimentation and erosion of glacial lake outburst floods along the Middle Pleistocene Scandinavian Ice Sheet (northern central Europe). Boreas 45 (2), 260-283, https://doi.org/10.1111/bor.12146. 